\title{
Synthesis and characterization of glucosamine-bound near-infrared probes for optical imaging
}

Cong Li, Tiffany R. Greenwood, Zaver M. Bhujwalla, and Kristine Glunde*

JHU ICMIC Program, The Russell H. Morgan Department of Radiology and Radiological Science, Johns Hopkins University School of Medicine, Baltimore, Maryland 21205

*Correspondence to: Dr. Kristine Glunde, JHU ICMIC Program, The Russell H. Morgan Department of Radiology and Radiological Science, Johns Hopkins University School of Medicine, 212 Traylor Building, 720 Rutland Avenue, Baltimore, Maryland 21205, USA. Tel: +1 410-6142705; Fax: +1410-614-1948; E-mail:kglunde@mri.jhu.edu

\section{Supporting Information}

\section{Table of content}

1. General experimental methods.

S2

2. Synthesis and characterization of compound $\mathbf{1}$.

S2-S6

3. Synthesis and characterization of compound 2.

S7-S10

4. Synthesis and characterization of compound $\mathbf{1 5}$.

S10-S11

5. Analytical HPLC analysis.

S12

6. Photospectroscopic analysis.

S13-S16

7. Cell culture.

S16-S17

8. Cytotoxicity experiments.

S17-S20

9. Cellular uptake of NIR compounds by HMECs

S20-S21

10. References.

S21

11. ${ }^{1} \mathrm{H},{ }^{13} \mathrm{C}$ NMR spectra of 3-9.

S22-S27

12. ${ }^{1} \mathrm{H},{ }^{13} \mathrm{C}$ NMR and MS spectra of $\mathbf{1}$.

S28-S29

13. ${ }^{1} \mathrm{H},{ }^{13} \mathrm{C}$ NMR spectra of $\mathbf{1 0}-\mathbf{1 4}$.

S30-S34

14. ${ }^{1} \mathrm{H},{ }^{13} \mathrm{C}$ NMR and MS spectra of 2 .

S35-S36

$15{ }^{1} \mathrm{H},{ }^{13} \mathrm{C}$ NMR and MS spectra of $\mathbf{1 5}$.

S37-S38 


\section{Experimental:}

General methods: Chemicals and solvents were purchased from Aldrich, Inc. (St. Louis, MO) and Alfa Aesar Inc. (Ward Hill, MA) unless otherwise specified. Dichloromethane (DCM) was dried over calcium hydride, and THF was desiccated by sodium metal and indicated by benzophenone. Water refers to high purity water with conductivity $\leq 0.04 \mu \mathrm{S} \mathrm{cm}^{-1}$, which was obtained from a PURITE purification system (Purite Ltd., Thame, UK). Synthetic reactions were monitored by TLC (Merck, Whitehouse Station, NJ, silica gel, $60 \AA \AA$ ) and HPLC using a Waters (Milford, MA) 1525 binary pump equipped with a Waters 2487 dual wavelength absorbance detector and Waters SYMMETRY ${ }^{\circledR} \mathrm{C}-18$ analytic column $(4.6 \mathrm{~mm} \times 100 \mathrm{~mm}) .{ }^{1} \mathrm{H}$ NMR spectra were recorded at 400 MHz on Varian Mercury 400 (Palo Alto, CA), and chemical shifts were reported in ppm relative to tetramethylsilane; ${ }^{13} \mathrm{C}$ NMR was measured at $100 \mathrm{MHz}$. Fast Atom Bombardment (FAB) mass spectra and High Resolution (HR) FAB mass spectra were obtained on a double sector JEOL JMS-A X505HA mass spectrometer (Peabody, MA); UV-VIS spectra were recorded on a Beckman Coulter DU $^{\circledR} 530$ UV-VIS spectrophotometer (Fullerton, CA). Fluorescence spectra were obtained on a Jobin Yvon-Spex ${ }^{\circledR}$ FluoroMax-3 spectrofluorometer (Edison, NJ). Wavelength scanning was carried out in increments of $1.0 \mathrm{~nm}$ with 0.1 second integration time, and the slit widths were set to 4.0 $\mathrm{nm} / 4.0 \mathrm{~nm}$ (excitation/emission). $\mathrm{pH}$ was monitored using a Mettler Toledo InLab ${ }^{\circledR}$ glass electrode (Columbus, OH). This electrode was operated by a Mettler Toledo MP220 pH meter (Columbus, $\mathrm{OH})$, which was calibrated using standard buffer solutions of $\mathrm{pH} 7.0$ and $\mathrm{pH} 4.0$ at $25^{\circ} \mathrm{C}$.

\section{Preparation of near-infrared fluorescent compound 1}

1-O-Boc-2- $N$-Boc- $\beta$-D-glucosamine (3). Compound 3 was prepared according to the previously

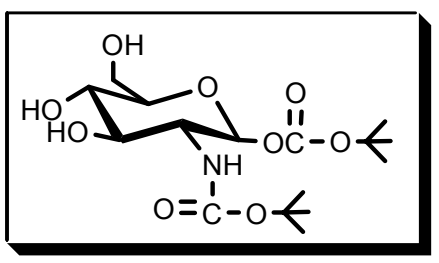
reported method. ${ }^{1}$ Sodium methoxide $(500 \mathrm{mg}, 9.28 \mathrm{mmol})$ and $\beta$-Dglucosamine $(2.0 \mathrm{~g}, 9.28 \mathrm{mmol})$ were added to $10 \mathrm{~mL}$ of methanol. The resulting suspension was stirred for $5 \mathrm{~min}$ at room temperature, and a white power was obtained following filtration. This powder was transferred to a $50 \mathrm{~mL}$ round bottom flask. Triethylamine $(1.42 \mathrm{~mL}$, $1.03 \mathrm{~g}, 10.2 \mathrm{mmol})$ and di-tert-butyl-dicarbonate $(2.35 \mathrm{~mL}, 2.23 \mathrm{~g}, 10.2 \mathrm{mmol})$ were added to this flask along with $10 \mathrm{~mL}$ anhydrous methanol, resulting in a thick white suspension. This suspension was stirred at room temperature under $\mathrm{N}_{2}$ for about $8 \mathrm{~h}$. The $N$-acylation product was monitored using TLC (2-propanol/water/ammonium hydroxide $=8: 1: 1 \mathrm{v} / \mathrm{v} / \mathrm{v}, \mathrm{R}_{\mathrm{f}}=0.75$ ) and stained with 
ninhydrin. Following removal of methanol, the residue was redissolved in a mixture of dioxine/water $(1: 1 \mathrm{v} / \mathrm{v}, 10 \mathrm{~mL})$ without purification. Triethylamine $(1.42 \mathrm{~mL}, 1.03 \mathrm{~g}, 10.2 \mathrm{mmol})$, 4dimethylaminopyridine (DMAP) $(80 \mathrm{mg}, 0.65 \mathrm{mmol})$, and di-tert-butyl-dicarbonate $(2.35 \mathrm{~mL}, 2.23$ $\mathrm{g}, 10.2 \mathrm{mmol}$ ) were added, and the clear solution was stirred at room temperature for $24 \mathrm{~h}$. The bisacylation product was monitored using TLC $\left(\mathrm{DCM} / \mathrm{ethyl}\right.$ acetate $/$ methanol $\left.=5: 2: 1 \mathrm{v} / \mathrm{v} / \mathrm{v}, \mathrm{R}_{\mathrm{f}}=0.45\right)$ and stained with ninhydrin. When the reaction was completed, $10 \mathrm{~mL}$ of water was added. This mixture was extracted with dichloromethane $(3 \times 20 \mathrm{~mL})$, and the organic phase was dried over anhydrous $\mathrm{Na}_{2} \mathrm{SO}_{4}$. After evaporation of the solvent in vacuo, the crude product was purified by silica gel chromatography and eluted with DCM/ethyl acetate/methanol $=100 / 40 / 20(\mathrm{v} / \mathrm{v} / \mathrm{v})$ to give the desired compound 3 as a white solid with a yield of 47\% (1.65 g, $4.36 \mathrm{mmol}) .{ }^{1} \mathrm{H}$ NMR (400 $\left.\mathrm{MHz}, \mathrm{CD}_{3} \mathrm{OD}\right): \delta 6.02(\mathrm{~s}, 1 \mathrm{H}), 3.87-3.52(\mathrm{~m}, 4 \mathrm{H}), 3.48-3.28(\mathrm{~m}, 2 \mathrm{H}), 1.49(\mathrm{~s}, 9 \mathrm{H}), 1.43(\mathrm{~s}, 9 \mathrm{H}) ;{ }^{13} \mathrm{C}$ NMR (100 MHz, CD $\left.{ }_{3} \mathrm{OD}\right): 158.17$ (C), 153.61 (C), 95.39 (CH), 83.69 (C), 80.45 (C), 76.10 (CH), $72.07(\mathrm{CH}), 71.46(\mathrm{CH}), 62.27(\mathrm{CH}), 55.87(\mathrm{CH}), 28.71\left(3 \times \mathrm{CH}_{3}\right), 27.91\left(3 \times \mathrm{CH}_{3}\right)$; HRFAB-MS: $\mathrm{C}_{16} \mathrm{H}_{30} \mathrm{O}_{9} \mathrm{~N}[\mathrm{M}+\mathrm{H}]^{+}$, found 380.1901 (33.2\%), calculated 380.1921 .

6-O-tosyl-1- $O$-Boc-2- $N$-Boc- $\beta$-D-glucosamine (4). A solution of $3(500 \mathrm{mg}, 1.30 \mathrm{mmol})$ in

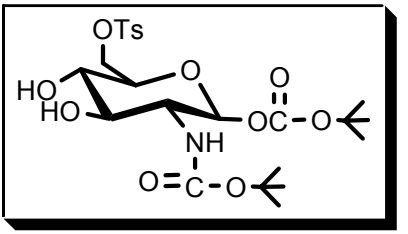
anhydrous pyridine $(15 \mathrm{~mL})$ was treated with $p$-toluenesulfonyl chloride (400 mg, $2.08 \mathrm{mmol}, 1.6$ equiv.) at $0^{\circ} \mathrm{C}$, and then stirred overnight at room temperature. The solvent was evaporated in vacuo and the residue was purified by column chromatography $(\mathrm{DCM} / \mathrm{ethyl}$ acetate/methanol $=$ 100/40/2, v/v/v) to provide 4 as colorless oil (603 mg, $1.13 \mathrm{mmol}$, yield: 87\%). ${ }^{1} \mathrm{H}$ NMR (400 MHz, $\left.\mathrm{CD}_{3} \mathrm{OD}\right): \delta 7.73(\mathrm{~d}, 2 \mathrm{H}, J=8.0 \mathrm{~Hz}), 7.38(\mathrm{~d}, 2 \mathrm{H}, J=8.0 \mathrm{~Hz}), 5.80(\mathrm{~s}, 1 \mathrm{H}), 4.25(\mathrm{dd}, 1 \mathrm{H}, J=10.8$, $1.6 \mathrm{~Hz}), 4.14(\mathrm{dd}, 1 \mathrm{H}, J=11.2,5.2 \mathrm{~Hz}), 3.71(\mathrm{ddd}, 1 \mathrm{H}, J=7.2,5.2,3.2 \mathrm{~Hz}), 3.51-3.50(\mathrm{~m}, 2 \mathrm{H}), 3.27$ (m, 1H), 2.42 (s, 3H), 1.43 (s, 9H), 1.38 (s, 9H); $\left.{ }^{13} \mathrm{C} \mathrm{NMR} \mathrm{(100} \mathrm{MHz,} \mathrm{CD}{ }_{3} \mathrm{OD}\right): 158.01$ (C), 153.21 (C), $146.46(\mathrm{C}), 134.14(\mathrm{C}), 130.96(2 \times \mathrm{CH}), 129.05(2 \times \mathrm{CH}), 94.97(\mathrm{CH}), 83.90(\mathrm{C}), 80.44(\mathrm{C})$, $73.43(\mathrm{CH}), 71.94(\mathrm{CH}), 71.06(\mathrm{CH}), 70.35(\mathrm{CH}), 55.54(\mathrm{CH}), 28.67\left(3 \times \mathrm{CH}_{3}\right), 27.88\left(3 \times \mathrm{CH}_{3}\right)$, $21.63\left(\mathrm{CH}_{3}\right)$; HRFAB-MS: $\mathrm{C}_{23} \mathrm{H}_{36} \mathrm{O}_{11} \mathrm{NS}[\mathrm{M}+\mathrm{H}]^{+}$, found $534.1981(100 \%)$, calculated 534.2009.

6-Azido-6-deoxy-1-O-Boc-2- $N$-Boc- $\beta$-D-glucosamine (5). Tosylate 4 (500 mg, $0.94 \mathrm{mmol}$ ) was dissolved in anhydrous DMF (15 mL), and sodium azide (487 mg, $7.50 \mathrm{mmol}, 8.0$ equiv.) was added. This mixture was stirred and heated to $80^{\circ} \mathrm{C}$ for $16 \mathrm{~h}$. The suspension was then allowed to 


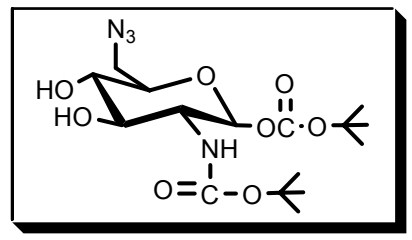

cool to room temperature and $20 \mathrm{~mL}$ of water was added. This mixture was extracted with ethyl acetate $(3 \times 20 \mathrm{~mL})$. The organic phase was collected and dried with anhydrous $\mathrm{Na}_{2} \mathrm{SO}_{4}$. After removing the solvent, a small amount was purified using column chromatography (dichloromethane/ethyl acetate/methanol $=100 / 40 / 5, \mathrm{v} / \mathrm{v} / \mathrm{v}$ ) resulting in $\mathbf{5}$ as light yellow solid (357 mg, 0.88 mmol, yield: 94\%). ${ }^{1} \mathrm{H}$ NMR (400 MHz, $\left.\mathrm{CD}_{3} \mathrm{OD}\right): \delta 5.88$ (d, $1 \mathrm{H}, J=4.4 \mathrm{~Hz}$ ), 3.68 (ddd, $1 \mathrm{H}, J=12.8,7.2,3.2 \mathrm{~Hz}), 3.56(\mathrm{dd}, 1 \mathrm{H}, J=12.0,5.4 \mathrm{~Hz}), 3.51-3.42(\mathrm{~m}, 2 \mathrm{H}), 3.35-3.26(\mathrm{~m}, 2 \mathrm{H})$, $1.41(\mathrm{~s}, 9 \mathrm{H}), 1.35$ (s, 9H); ${ }^{13} \mathrm{C}$ NMR (100 MHz, CD $\left.{ }_{3} \mathrm{OD}\right): 158.17$ (C), $153.36(\mathrm{C}), 95.13(\mathrm{CH}), 83.91$ (C), $80.53(\mathrm{C}), 74.83(\mathrm{CH}), 72.30(\mathrm{CH}), 71.97(\mathrm{CH}), 55.79(\mathrm{CH}), 52.29(\mathrm{CH}), 28.69\left(3 \times \mathrm{CH}_{3}\right)$, $27.88\left(3 \times \mathrm{CH}_{3}\right)$; HRFAB-MS: $\mathrm{C}_{16} \mathrm{H}_{29} \mathrm{O}_{8} \mathrm{~N}_{4}[\mathrm{M}+\mathrm{H}]^{+}$, found $405.2002(15.3 \%)$, calculated 405.1985 .

6-amine-6-deoxy-1-O-Boc-2- $N$-Boc- $\beta$-D-glucosamine (6). Azide 5 (500 mg, $1.24 \mathrm{mmol}$ ) was

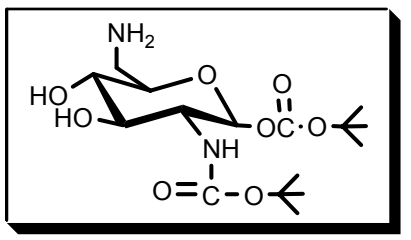
dissolved in $15 \mathrm{~mL}$ of $\mathrm{THF} / \mathrm{H}_{2} \mathrm{O}(5 / 1 \mathrm{v}: \mathrm{v})$, and triphenylphosphine (390 mg, 1.49 mmol, 1.2 equiv.) was added. This reaction mixture was stirred at room temperature for $14 \mathrm{~h}$. After evaporating the solvent in vacuo, column chromatography (dichloromethane/methanol/ammonium hydroxide $=100 / 35 / 2, \mathrm{v} / \mathrm{v} / \mathrm{v})$ afforded 6 as white solid $(347 \mathrm{mg}, 0.92$ mmol, yield: 74\%). ${ }^{1} \mathrm{H}$ NMR (400 MHz, $\left.\mathrm{CD}_{3} \mathrm{OD}\right): \delta 5.94(\mathrm{~d}, 1 \mathrm{H}, J=3.2 \mathrm{~Hz}), 3.62-3.51(\mathrm{~m}, 3 \mathrm{H})$, 3.28-3.21 (m, 1H), $2.96(\mathrm{dd}, 1 \mathrm{H}, J=13.6,2.8 \mathrm{~Hz}), 2.72(\mathrm{dd}, 1 \mathrm{H}, J=13.6,7.2 \mathrm{~Hz}), 1.45(\mathrm{~s}, 9 \mathrm{H}), 1.40$ (s, 9H); ${ }^{13} \mathrm{C}$ NMR (100 MHz, CD $\left.3 \mathrm{OD}\right): 158.19$ (C), 153.61 (C), 95.27 (CH), 83.77 (C), 80.47 (C), $75.75(\mathrm{CH}), 73.26(\mathrm{CH}), 71.98(\mathrm{CH}), 55.93(\mathrm{CH}), 43.59(\mathrm{CH}), 28.71\left(3 \times \mathrm{CH}_{3}\right), 27.90\left(3 \times \mathrm{CH}_{3}\right)$; HRFAB-MS: $\mathrm{C}_{16} \mathrm{H}_{31} \mathrm{O}_{8} \mathrm{~N}_{2}[\mathrm{M}+\mathrm{H}]^{+}$, found 379.2089 (30.2\%), calculated 379.2080.

Succinimidyl 3-(4-hydroxyphenyl) propionate (7) NHS-ester 7 was prepared according to a

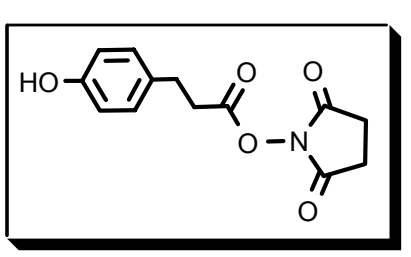
previously published procedure. ${ }^{2}$ A solution of DCC (1.36 g, $6.6 \mathrm{mmol}$, 1.1 equiv.) in ethyl acetate $(10 \mathrm{~mL})$ was added dropwise to an ice-cooled solution of 3-(4-hydrophenyl) propionic acid (1.0 g, $6.02 \mathrm{mmol})$ and $\mathrm{N}$ hydrosuccinimide (762 mg, $6.62 \mathrm{mmol}, 1.1$ equiv.) in $15 \mathrm{~mL}$ of ethyl acetate within a period of $15 \mathrm{~min}$. After stirring for $16 \mathrm{~h}$, this mixture was allowed to warm up to room temperature, and the white precipitate was filtered off. The resulting crude product was recrystallized in isopropanol as a white solid (1.14 g, $4.33 \mathrm{mmol}$, yield: $72 \%)$. 


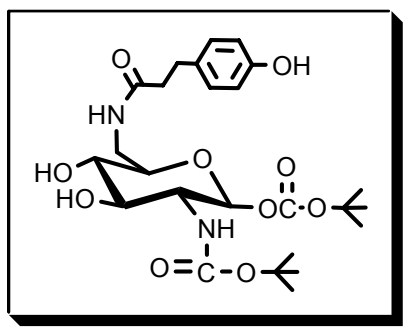

Compound 6 (200 mg, $0.53 \mathrm{mmol})$ and NHS-ester 7 (167 mg, 0.63 mmol, 1.2 equiv.) were added to $10 \mathrm{~mL}$ of anhydrous dichloromethane. This suspension was stirred at room temperature for $2 \mathrm{~h}$, resulting in a clear solution. The solvent was removed, and the residue was purified using column chromatography (ethyl acetate/hexane $=100 / 20, \mathrm{v} / \mathrm{v}$ ), which offered 8 as a white solid (234 $\mathrm{mg}, 0.45 \mathrm{mmol}$, yield: $84 \%) .{ }^{1} \mathrm{H}$ NMR (400 MHz, CD 3 OD): $\delta 6.97(\mathrm{~d}, 2 \mathrm{H}, J=8.4 \mathrm{~Hz}), 6.67$ (d, 2H, $J=8.8 \mathrm{~Hz}), 5.91$ (d, 1H, $J=2.4$ $\mathrm{Hz}), 3.62-3.57$ (m, 3H), 3.50 (dd, 1H, $J=14.4,2.4 \mathrm{~Hz}), 3.36$ (dd, 1H, $J=14.0,6.4 \mathrm{~Hz}), 3.13(\mathrm{t}, 1 \mathrm{H}$, $J=9.6 \mathrm{~Hz}), 2.76(\mathrm{t}, 2 \mathrm{H}, J=7.2 \mathrm{~Hz}), 2.41(\mathrm{t}, 2 \mathrm{H}, J=6.8 \mathrm{~Hz}), 1.42(\mathrm{~s}, 9 \mathrm{H}), 1.39(\mathrm{~s}, 9 \mathrm{H}) ;{ }^{13} \mathrm{C} \mathrm{NMR}$ (100 MHz, CD $\left.\mathrm{CD}_{3} \mathrm{OD}\right): 176.11$ (C), 158.12 (C), 156.59 (C), 153.49 (C), 132.84 (C), 130.23 (2× CH), $116.28(2 \times \mathrm{CH}), 95.22(\mathrm{CH}), 83.77(\mathrm{C}), 80.48(\mathrm{C}), 74.15(\mathrm{CH}), 72.70(\mathrm{CH}), 71.53(\mathrm{CH}), 55.78$ $(\mathrm{CH}), 41.07(\mathrm{CH}), 39.21\left(\mathrm{CH}_{2}\right), 32.20\left(\mathrm{CH}_{2}\right), 28.70\left(3 \times \mathrm{CH}_{3}\right), 27.89\left(3 \times \mathrm{CH}_{3}\right)$; HRFAB-MS: $\mathrm{C}_{25} \mathrm{H}_{39} \mathrm{O}_{10} \mathrm{~N}_{2}[\mathrm{M}+\mathrm{H}]^{+}$, found $527.2582(13.6 \%)$, calculated 527.2605.

6- $\{N$-[3-[4-phenylhydroxyl-2-[2-[2-[3-[2-[1,3-dihydro-3,3-dimethyl-1-(4-sulfobutyl)]-2H-indol-2ylidene]-ethylidene]-1-cyclohexen-1-yl]-ethenyl]-3,3-dimethyl-1-(4-sulfobutyl)-3H-indolium hydroxide]-propionyl]-amide \}-6-deoxy-1-O-Boc-2- $N$-Boc- $\beta$-D-glucosamine (9). $\mathrm{NaH}(60 \%$ in

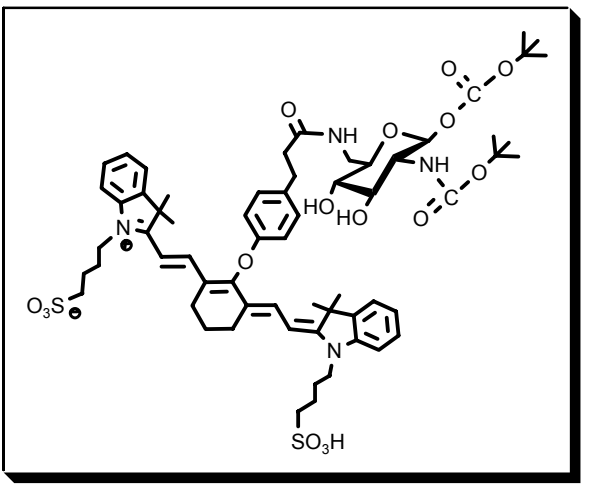
mineral oil) (4.2 $\mathrm{mg}, 0.11 \mathrm{mmol}, 1.1$ equiv.) was added to a solution of compound $8(50 \mathrm{mg}, 0.095 \mathrm{mmol})$ in $5 \mathrm{~mL}$ anhydrous DMF. This mixture was stirred at room temperature for about $15 \mathrm{~min}$. Subsequently, IR-783 (42.7 $\mathrm{mg}, 0.057 \mathrm{mmol}, 0.6$ equiv.) dissolved in $0.5 \mathrm{~mL}$ of $\mathrm{DMF}$ was added dropwise. The mixture was stirred for another 20 min at room temperature, and a small piece of dry ice was used to quench the reaction. DMF was evaporated in vacuo at $50^{\circ} \mathrm{C}$. The crude product was purified by column chromatography (acetonitrile $/ \mathrm{H}_{2} \mathrm{O}=100 / 10$, $\mathrm{v} / \mathrm{v}$ ) to give 9 as deep green solid (47 mg, $0.038 \mathrm{mmol}$, yield: 66\%). ${ }^{1} \mathrm{H}$ NMR (400 MHz, $\mathrm{CD}_{3} \mathrm{OD}$ ): $\delta 7.93(\mathrm{~d}, 2 \mathrm{H}, J=14.4 \mathrm{~Hz}), 7.35-7.14(\mathrm{~m}, 10 \mathrm{H}), 7.00(\mathrm{~d}, 2 \mathrm{H}, J=9.2 \mathrm{~Hz}), 6.15(\mathrm{dd}, 2 \mathrm{H}, J=2.4,14.0$ Hz), $5.88(\mathrm{~s}, 1 \mathrm{H}), 4.10(\mathrm{br}, 4 \mathrm{H}), 3.61-3.45(\mathrm{~m}, 3 \mathrm{H}), 3.28-3.07(\mathrm{~m}, 3 \mathrm{H}), 2.87-2.79(\mathrm{~m}, 5 \mathrm{H}), 2.71(\mathrm{br}$, $3 \mathrm{H}), 2.60(\mathrm{t}, 2 \mathrm{H}, J=6.4 \mathrm{~Hz}), 2.40(\mathrm{t}, 2 \mathrm{H}, J=7.6 \mathrm{~Hz}), 2.00-1.82(\mathrm{~m}, 10 \mathrm{H}), 1.68(\mathrm{~s}, 12 \mathrm{H}), 1.40(\mathrm{~s}$, 
9H), 1.29 (s, 9H); ${ }^{13} \mathrm{C}$ NMR (100 MHz, CD $\left.{ }_{3} \mathrm{OD}\right): 175.52$ (C), 173.50 (C), 173.11 (C), 165.54 (C), $159.96(\mathrm{C}), 158.12(\mathrm{C}), 153.56(\mathrm{C}), 143.78(\mathrm{C}), 143.58(\mathrm{CH}), 143.45(\mathrm{C}), 142.43(\mathrm{CH}), 142.25(\mathrm{C})$, $131.29(2 \times \mathrm{CH}), 129.77(2 \times \mathrm{CH}), 126.09(2 \times \mathrm{CH}), 125.90(\mathrm{C}), 123.91(\mathrm{C}), 123.47(\mathrm{CH}), 123.36$ $(\mathrm{CH}), 115.84(2 \times \mathrm{C}), 112.04(2 \times \mathrm{C}), 111.91(\mathrm{C}), 101.07(2 \times \mathrm{C}), 100.58(\mathrm{C}), 95.22(\mathrm{CH}), 83.76$ (C), $80.43(\mathrm{C}), 74.15(\mathrm{CH}), 73.02(\mathrm{CH}), 71.61(\mathrm{CH}), 55.94(\mathrm{CH}), 51.78\left(2 \times \mathrm{CH}_{2}\right), 50.22\left(2 \times \mathrm{CH}_{2}\right)$, $49.85\left(\mathrm{CH}_{2}\right), 44.82\left(2 \times \mathrm{CH}_{2}\right), 41.35(\mathrm{C}), 38.87(\mathrm{C}), 31.97\left(\mathrm{CH}_{2}\right), 28.73\left(3 \times \mathrm{CH}_{3}\right), 28.67\left(2 \times \mathrm{CH}_{3}\right)$, $28.24\left(3 \times \mathrm{CH}_{3}\right), 27.95\left(2 \times \mathrm{CH}_{3}\right), 27.18\left(2 \times \mathrm{CH}_{2}\right), 25.19\left(2 \times \mathrm{CH}_{2}\right), 23.57\left(\mathrm{CH}_{2}\right), 22.45\left(\mathrm{CH}_{2}\right)$; FAB-MS: $\mathrm{C}_{63} \mathrm{H}_{83} \mathrm{O}_{16} \mathrm{~N}_{4} \mathrm{~S}_{2}[\mathrm{M}+\mathrm{H}]^{+}$, found $1215.5(11.6 \%)$, calculated 1215.5.

6- $\{\mathrm{N}$-[3-[4-phenylhydroxyl-2-[2-[2-[3-[2-[1,3-dihydro-3,3-dimethyl-1-(4-sulfobutyl)]-2H-indol-2ylidene]-ethylidene]-1-cyclohexen-1-yl]-ethenyl]-3,3-dimethyl-1-(4-sulfobutyl)-3H-indolium hydroxide]-propionyl]-amide\}-6-deoxy- $\beta$-D-glucosamine (1). Compound 9 (100 mg, $0.081 \mathrm{mmol}$ )

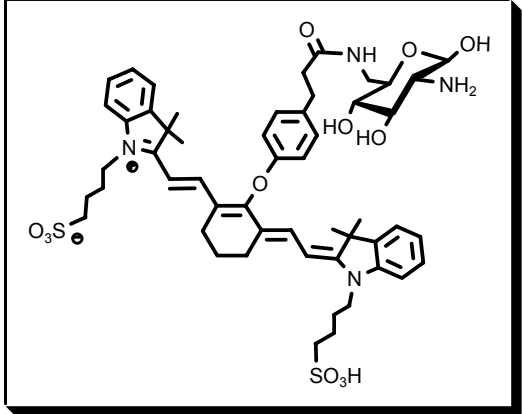
was dissolved in a mixture $(6 \mathrm{~mL})$ of dichloromethane and trifluoacetic acid $(1: 2, \mathrm{v} / \mathrm{v})$. This solution was stirred at room temperature for about $3 \mathrm{~h}$. After removing the solvent, the residue was dissolved in $0.5 \mathrm{~mL}$ of methanol. Diethyl ether $(10$ $\mathrm{mL})$ was added to this solution, and the final product $1(75 \mathrm{mg}$, $0.073 \mathrm{mmol}, 90 \%$ ) was obtained after filtration as a deep green powder. ${ }^{1} \mathrm{H}$ NMR (400 MHz, $\left.\mathrm{CD}_{3} \mathrm{OD}\right): \delta 7.94(\mathrm{~d}, 2 \mathrm{H}, J=14.4$ $\mathrm{Hz}), 7.35$ (dd, 4H, $J=6.8,8.0 \mathrm{~Hz}), 7.26$ (q, 4H, $J=8.4 \mathrm{~Hz}), 7.18$ (t, 2H, $J=7.6 \mathrm{~Hz}), 7.00$ (d, 2H, $J$ $=8.4 \mathrm{~Hz}), 6.15(\mathrm{~d}, 2 \mathrm{H}, J=14.4 \mathrm{~Hz}), 5.25(\mathrm{~d}, 1 \mathrm{H}, 3.6 \mathrm{~Hz}), 4.12(\mathrm{br}, 4 \mathrm{H}), 3.80-3.74(\mathrm{~m}, 1 \mathrm{H}), 3.51-$ $3.41(\mathrm{~m}, 2 \mathrm{H}), 3.29-3.18(\mathrm{~m}, 3 \mathrm{H}), 3.15-3.11(\mathrm{~m}, 1 \mathrm{H}), 2.88-2.81(\mathrm{br}, 5 \mathrm{H}), 2.73(\mathrm{br}, 4 \mathrm{H}), 2.44(\mathrm{t}, 2 \mathrm{H}, J$ $=7.6 \mathrm{~Hz}), 2.03-1.78(\mathrm{br}, 10 \mathrm{H}), 1.30(\mathrm{~s}, 12 \mathrm{H}) ;{ }^{13} \mathrm{C} \mathrm{NMR}\left(100 \mathrm{MHz}, \mathrm{CD}_{3} \mathrm{OD}\right): 174.36(2 \times \mathrm{C}), 172.32$ $(2 \times \mathrm{C}), 164.33(\mathrm{C}), 158.76(\mathrm{C}), 142.46(2 \times \mathrm{CH}), 142.22(\mathrm{C}), 141.25(2 \times \mathrm{CH}), 135.42(\mathrm{C}), 130.21$ $(2 \times \mathrm{C}), 128.67(2 \times \mathrm{C}), 124.99(2 \times \mathrm{CH}), 122.32(2 \times \mathrm{CH}), 122.27(2 \times \mathrm{CH}), 114.69(2 \times \mathrm{CH})$, $110.95(2 \times \mathrm{CH}), 99.97(2 \times \mathrm{CH}), 93.48(\mathrm{CH}), 74.94(\mathrm{CH}), 72.05(\mathrm{CH}), 70.37(\mathrm{CH}), 57.64(\mathrm{CH})$, $55.02(\mathrm{CH}), 50.70\left(2 \times \mathrm{CH}_{2}\right), 49.09\left(2 \times \mathrm{CH}_{2}\right), 43.72\left(2 \times \mathrm{CH}_{2}\right), 40.24\left(\mathrm{CH}_{2}\right), 37.66\left(\mathrm{CH}_{2}\right), 30.74(2$ $\times \mathrm{C}), 27.12\left(2 \times \mathrm{CH}_{3}\right), 26.08\left(2 \times \mathrm{CH}_{3}\right), 24.07\left(2 \times \mathrm{CH}_{2}\right), 22.41\left(2 \times \mathrm{CH}_{2}\right), 21.32\left(\mathrm{CH}_{2}\right)$; HRFABMS: $\mathrm{C}_{53} \mathrm{H}_{67} \mathrm{O}_{12} \mathrm{~N}_{4} \mathrm{~S}_{2}[\mathrm{M}]^{+}$, found $1015.4221(1.3 \%)$, calculated 1015.4197. 


\section{Preparation of near-infrared fluorescent compound 2}

3-(4-iodobutoxy)-phenyl acetate (10). Resorinol monoacetate $(1.0 \mathrm{~g}, 6.57 \mathrm{mmol})$ was added to a

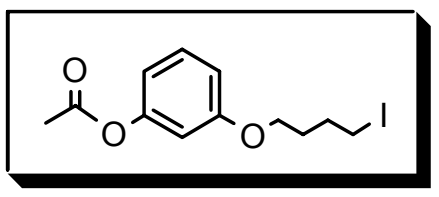
mixture of $10 \mathrm{~mL}$ acetone and $\mathrm{K}_{2} \mathrm{CO}_{3}(1.81 \mathrm{~g}, 13.15 \mathrm{mmol}, 2.0$ equiv.). 1,4-diiodobutane (4.08 g, $13.15 \mathrm{mmol}, 2.0$ equiv.) dissolved in $5 \mathrm{~mL}$ acetone was also added. This suspension was stirred at $50^{\circ} \mathrm{C}$ under $\mathrm{N}_{2}$ for two days. After evaporating the solvent, product $\mathbf{1 0}$ was obtained using column chromatography purification (hexane/ethyl acetate $=200 / 10, \mathrm{v} / \mathrm{v}$ ) as a light yellow liquid (yield: $64 \%, 1.41 \mathrm{~g}, 4.20 \mathrm{mmol}) .{ }^{1} \mathrm{H}$ NMR $\left(400 \mathrm{MHz}, \mathrm{CDCl}_{3}\right): \delta 7.26(\mathrm{t}, 1 \mathrm{H}, J=8.0$ $\mathrm{Hz}), 6.76(\mathrm{dd}, 1 \mathrm{H}, J=8.2,5.4 \mathrm{~Hz}), 6.68(\mathrm{dd}, 1 \mathrm{H}, J=8.0,5.4 \mathrm{~Hz}), 6.63(\mathrm{t}, 1 \mathrm{H}, J=1.6 \mathrm{~Hz}), 3.96(\mathrm{t}$, $2 \mathrm{H}, J=3.6 \mathrm{~Hz}), 3.24(\mathrm{t}, 2 \mathrm{H}, J=4.2 \mathrm{~Hz}), 2.28(\mathrm{~s}, 3 \mathrm{H}), 2.02(\mathrm{p}, 2 \mathrm{H}, J=3.6 \mathrm{~Hz}), 1.88(\mathrm{p}, 2 \mathrm{H}, J=3.6$ $\mathrm{Hz}) ;{ }^{13} \mathrm{C}$ NMR (100 MHz, CD $\left.\mathrm{OD}\right): 169.25$ (C), 159.71 (C), 151.34 (C), $129.87(\mathrm{CH}), 113.79(\mathrm{CH})$, $111.97(\mathrm{CH}), 108.02(\mathrm{CH}), 66.68\left(\mathrm{CH}_{2}\right), 29.96(\mathrm{CH}), 29.90\left(\mathrm{CH}_{2}\right), 21.28\left(\mathrm{CH}_{3}\right), 6.27\left(\mathrm{CH}_{2}\right)$; HRFAB-MS: $\mathrm{C}_{12} \mathrm{H}_{16} \mathrm{O}_{3} \mathrm{I}[\mathrm{M}+\mathrm{H}]^{+}$, found 335.0130 (81.6\%), calculated 335.0144.

6- $\{N$-[4-(3-phenyl acetate)-oxybutyl]-amine $\}-6-d e o x y-1-O-B o c-2-N$-Boc- $\beta$-D-glucosamine (11).

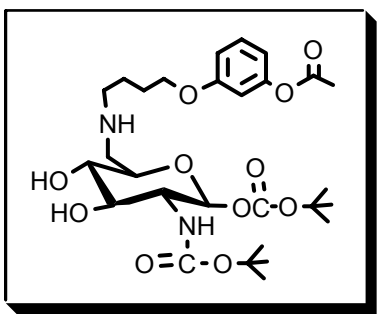
Amine 6 (300 mg, $0.79 \mathrm{mmol})$ and iodide $10(264 \mathrm{mg}, 0.79 \mathrm{mmol}, 1.0$ equiv.) were dissolved in $10.0 \mathrm{~mL}$ of acetonitrile, and $N, N$-diisopropylethylamine ( $102.1 \mathrm{mg}, 0.79 \mathrm{mmol}, 1.0$ equiv.) was added as auxiliary base. This mixture was stirred at $80^{\circ} \mathrm{C}$ under $\mathrm{N}_{2}$ for about $14 \mathrm{~h}$. The solvent was removed, and the residue was purified by column chromatography (dichloromethane/ethyl acetate/methanol = 100/40/15, v/v/v) affording 11 as light yellow oil (310 mg, $0.53 \mathrm{mmol}$, yield: 67\%). ${ }^{1} \mathrm{H}$ NMR (400 MHz, $\left.\mathrm{CD}_{3} \mathrm{OD}\right): \delta 7.24(\mathrm{t}, 1 \mathrm{H}, J=8.0$ $\mathrm{Hz}), 6.67(\mathrm{dd}, 1 \mathrm{H}, J=8.0,5.6 \mathrm{~Hz}), 6.66-6.62(\mathrm{~m}, 2 \mathrm{H}), 6.00(\mathrm{~d}, 1 \mathrm{H}, J=3.2 \mathrm{~Hz}), 3.98(\mathrm{br}, 2 \mathrm{H}), 3.86$ (t, $1 \mathrm{H}, J=9.2 \mathrm{~Hz}), 3.65-3.55(\mathrm{~m}, 2 \mathrm{H}), 3.28-3.24(\mathrm{~m}, 2 \mathrm{H}), 3.06(\mathrm{dd}, 1 \mathrm{H}, J=13.2,9.2 \mathrm{~Hz}), 2.97$ (br, 2H), $2.22(\mathrm{~s}, 3 \mathrm{H}), 1.81(\mathrm{br}, 4 \mathrm{H}), 1.45(\mathrm{~s}, 9 \mathrm{H}), 1.40(\mathrm{~s}, 9 \mathrm{H}) ;{ }^{13} \mathrm{C}$ NMR (100 MHz, CD $\left.3 \mathrm{OD}\right): 171.15$ (C), 161.09 (C), 158.21 (C), 153.46 (C), 153.19 (C), 130.89 (CH), $114.98(\mathrm{CH}), 113.06(\mathrm{CH})$, $109.44(\mathrm{CH}), 94.89(\mathrm{CH}), 84.19(\mathrm{C}), 80.60(\mathrm{C}), 73.59(\mathrm{CH}), 71.63(2 \times \mathrm{CH}), 68.48(\mathrm{CH}), 55.70$ $(\mathrm{CH}), 49.85\left(\mathrm{CH}_{2}\right), 49.16\left(\mathrm{CH}_{2}\right), 28.69\left(3 \times \mathrm{CH}_{3}\right), 27.91\left(3 \times \mathrm{CH}_{3}\right), 27.40\left(\mathrm{CH}_{2}\right), 24.65\left(\mathrm{CH}_{2}\right), 21.00$ $\left(\mathrm{CH}_{3}\right)$; HRFAB-MS: $\mathrm{C}_{28} \mathrm{H}_{45} \mathrm{O}_{11} \mathrm{~N}_{2}[\mathrm{M}+\mathrm{H}]^{+}$, found 585.3037 (100.0\%), calculated 585.3023. 


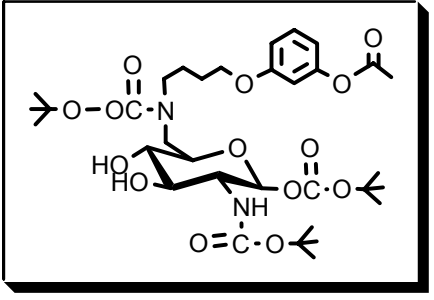

6-\{[N-(4-(3-phenyl acetate)-oxybutyl)]-(N'-Boc)-amine $\}$-6-deoxy-1$O$-Boc-2- $N$-Boc- $\beta$-D-glucosamine (12). Triethylamine $(68 \mathrm{mg}, 0.68$ mmol, 2.0 equiv.) and di-tert-butyl dicarbonate $(89 \mathrm{mg}, 0.41 \mathrm{mmol}$, 1.2 equiv.) were added to a solution of compound 11 (200 mg, 0.34 mmol) in $10 \mathrm{~mL}$ of methanol. This reaction mixture was stirred at room temperature for about $5 \mathrm{~h}$. The resulting tris-Boc-protected product $\mathbf{1 2}(221 \mathrm{mg}, 0.32 \mathrm{mmol}$, yield: 95\%) was isolated by column chromatography (dichloromethane/ethyl acetate/methanol = 100/40/3, v/v/v) as a glass-like solid. ${ }^{1} \mathrm{H}$ NMR (400 MHz, $\left.\mathrm{CD}_{3} \mathrm{OD}\right): \delta 7.15$ (t, $1 \mathrm{H}, J=8.0 \mathrm{~Hz}$ ), 6.69 (dd, 1H, $J=8.4,1.6 \mathrm{~Hz}$ ), 6.57-6.54 (m, 2H), 5.84 (s, 1H), 3.86 (br, 2H), 3.71-3.65 (m, 1H), 3.59$3.45(\mathrm{~m}, 3 \mathrm{H}), 3.33-2.95(\mathrm{~m}, 4 \mathrm{H}), 2.15(\mathrm{~s}, 3 \mathrm{H}), 1.61(\mathrm{br}, 4 \mathrm{H}), 1.33(\mathrm{~s}, 27 \mathrm{H}) ;{ }^{13} \mathrm{C} \mathrm{NMR}(100 \mathrm{MHz}$, $\left.\mathrm{CD}_{3} \mathrm{OD}\right): 170.96$ (C), 161.23 (C), 158.06 (C), 157.17 (C), 153.36 (C), 153.09 (C), $130.74(\mathrm{CH})$, $114.71(\mathrm{CH}), 113.04(\mathrm{CH}), 109.33(\mathrm{CH})$, [95.09 (CH); $94.95(\mathrm{CH})], 83.68(\mathrm{C})$, [81.27 (C); 80.95 (C)], $80.42(\mathrm{C}), 76.00\left(\mathrm{CH}_{2}\right)$, [73.73 (CH); $\left.73.18(\mathrm{CH})\right]$, [(72.20 (CH); $\left.71.62(\mathrm{CH})\right],[68.94(\mathrm{CH})$; $68.77(\mathrm{CH})], 55.71(\mathrm{CH}), 50.21\left(\mathrm{CH}_{2}\right), 49.82\left(\mathrm{CH}_{2}\right), 28.71\left(3 \times \mathrm{CH}_{3}\right), 27.95\left(3 \times \mathrm{CH}_{3}\right), 27.50(3 \times$ $\left.\mathrm{CH}_{3}\right), 26.03\left(\mathrm{CH}_{2}\right), 25.61\left(\mathrm{CH}_{2}\right), 21.02\left(\mathrm{CH}_{3}\right)$; HRFAB-MS: $\mathrm{C}_{33} \mathrm{H}_{53} \mathrm{O}_{13} \mathrm{~N}_{2}[\mathrm{M}+\mathrm{H}]^{+}$, found 685.3551 (43.8\%), calculated 685.3548 .

6-\{[N-(4-(3-phenol)-oxybutyl)]-( $N$ '-Boc)-amine $\}-6-$ deoxy-1- $O$-Boc-2- $N$-Boc- $\beta$-D-glucosamine (13).

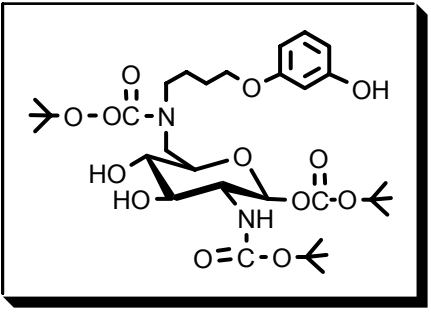

A catalytic dose of sodium methyloxide was added to a solution of compound 12 (200 mg, $0.29 \mathrm{mmol})$ in $5 \mathrm{~mL}$ of methanol. This mixture was stirred at room temperature for about $2 \mathrm{~h}$. The hydrolyzed product $\mathbf{1 3}$ was isolated by column chromatography (dichloromethane/ethyl acetate/methanol $=100 / 40 / 3, \mathrm{v} / \mathrm{v} / \mathrm{v}$ ) as a light yellow powder, achieving a yield of $98 \%(154 \mathrm{mg}, 0.28 \mathrm{mmol}) .{ }^{1} \mathrm{H}$ NMR (400 MHz, CD 3 OD): $\delta 6.99(\mathrm{t}, 1 \mathrm{H}, J=8.8 \mathrm{~Hz}), 6.36-6.31(\mathrm{~m}, 3 \mathrm{H}), 5.90(\mathrm{br}, 1 \mathrm{H}), 3.88(\mathrm{br}$, $2 \mathrm{H}), 3.78-3.67(\mathrm{~m}, 1 \mathrm{H}), 3.65-3.51(\mathrm{~m}, 3 \mathrm{H}), 3.43-3.26(\mathrm{~m}, 2 \mathrm{H}), 3.22-3.03(\mathrm{~m}, 2 \mathrm{H}), 1.66(\mathrm{br}, 4 \mathrm{H})$, 1.41 (br, 18H), 1.39 (s, 9H); ${ }^{13} \mathrm{C}$ NMR (100 MHz, CD $\left.3 \mathrm{OD}\right): 161.64$ (C), 159.54 (C), 158.14 (C), $157.22(\mathrm{C}), 153.37(\mathrm{C}), 130.79(\mathrm{CH}), 108.70(\mathrm{CH}), 106.71(\mathrm{CH}), 102.89(\mathrm{CH}),[95.11(\mathrm{CH}) ; 94.95$ $(\mathrm{CH})$ ], $83.72(\mathrm{C}),[81.30(\mathrm{C}) ; 81.00(\mathrm{C})], 80.48(\mathrm{C}), 74.98\left(\mathrm{CH}_{2}\right)$, [73.80 (CH); $\left.73.24(\mathrm{CH})\right],[(72.19$ $(\mathrm{CH}) ; 71.67(\mathrm{CH})],[68.52(\mathrm{CH}) ; 68.32(\mathrm{CH})], 55.83(\mathrm{CH}), 50.21\left(\mathrm{CH}_{2}\right), 49.85\left(\mathrm{CH}_{2}\right), 28.69(3 \times$ 
$\left.\mathrm{CH}_{3}\right), 27.94\left(3 \times \mathrm{CH}_{3}\right), 27.63\left(3 \times \mathrm{CH}_{3}\right), 26.05\left(\mathrm{CH}_{2}\right), 25.64\left(\mathrm{CH}_{2}\right) ;$ HRFAB-MS: $\mathrm{C}_{31} \mathrm{H}_{51} \mathrm{O}_{12} \mathrm{~N}_{2}$ $[\mathrm{M}+\mathrm{H}]^{+}$, found $543.3454(47.9 \%)$, calculated 543.3442 .

6- $\{N$-[4-[3-phenyloxyl-2-[2-[2-[3-[2-[1,3-dihydro-3,3-dimethyl-1-(4-sulfobutyl)]-2H-indol-2ylidene]-ethylidene]-1-cyclohexen-1-yl]-ethenyl]-3,3-dimethyl-1-(4-sulfobutyl)-3H-indolium

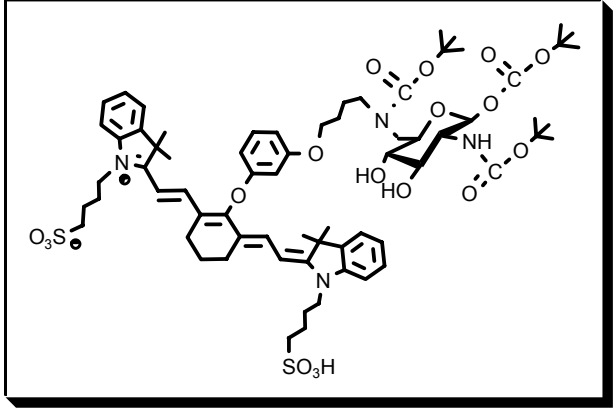

hydroxide]-butyloxy]-(N'-Boc)-amine \}-6-deoxy-1-O-Boc$2-N$-Boc- $\beta$-D-glucosamine (14). $\mathrm{NaH}(60 \%$ in mineral oil) (3.4 $\mathrm{mg}, 0.086 \mathrm{mmol}, 1.1$ equiv.) was added to a solution of compound 13 (50 mg, $0.078 \mathrm{mmol})$ in $5 \mathrm{~mL}$ of anhydrous DMF. This mixture was stirred at room temperature for about 15 minutes. IR-783 (35 mg, $0.047 \mathrm{mmol}, 0.6$ equiv.) dissolved in $0.5 \mathrm{~mL}$ of DMF was added dropwise to this mixture. The reaction mixture was stirred for another $20 \mathrm{~min}$ at room temperature, and a small piece of dry ice was used to quench the reaction. DMF was evaporated under vacuum at $50^{\circ} \mathrm{C}$. The crude product was purified by column chromatography (acetonitrile $/ \mathrm{H}_{2} \mathrm{O}=100 / 10, \mathrm{v} / \mathrm{v}$ ) to give $\mathbf{1 4}$ as deep green solid (47 mg, $0.035 \mathrm{mmol}$, yield: 74\%). ${ }^{1} \mathrm{H}$ NMR (400 MHz, $\left.\mathrm{CD}_{3} \mathrm{OD}\right): \delta 7.94$ (d, 2H, $J=14.0$ $\mathrm{Hz}), 7.35-7.19$ (m, 6H), 7.16 (t, 2H, $J=7.6 \mathrm{~Hz}), 6.74-6.56(\mathrm{~m}, 4 \mathrm{H}), 6.16(\mathrm{~d}, 2 \mathrm{H}, J=10.0 \mathrm{~Hz}), 5.90$ (s, 1H), 4.10 (br, 4H), 3.96 (br, 3H), 3.77-3.37 (m, 4H), 3.32-3.23 (m, 3H), 2.87-2.82 (m, 4H), 2.72 (br, 4H), 1.95 (br, 10H), 1.68 (br, 4H), 1.39 (s, 18H), $1.38(\mathrm{~s}, 12 \mathrm{H}), 1.33(\mathrm{~s}, 9 \mathrm{H}) ;{ }^{13} \mathrm{C}$ NMR (100 $\left.\mathrm{MHz}, \mathrm{CD}_{3} \mathrm{OD}\right): 172.33(2 \times \mathrm{C}), 164.10$ (C), 163.84 (C), 163.28 (C), $161.18(2 \times \mathrm{C}), 156.99(\mathrm{C})$, $156.36(\mathrm{C}), 156.30(\mathrm{C}), 152.30(\mathrm{C}), 142.42(\mathrm{CH}), 142.22(2 \times \mathrm{C}), 141.29(\mathrm{CH}), 130.91(\mathrm{C}), 128.67$ $(2 \times \mathrm{CH}), 125.00(2 \times \mathrm{CH}), 122.32(2 \times \mathrm{CH}), 122.18(2 \times \mathrm{CH}), 110.94(2 \times \mathrm{CH}), 101.76(2 \times \mathrm{CH})$, $100.03(2 \times \mathrm{CH}), 94.00(\mathrm{CH}), 82.55(\mathrm{C}), 80.13(\mathrm{C}), 79.28(\mathrm{C}), 73.92(\mathrm{CH}), 72.11(\mathrm{CH}), 71.13(\mathrm{CH})$, $70.55(\mathrm{CH}), 67.87(\mathrm{CH}), 54.87(\mathrm{CH}), 50.63\left(2 \times \mathrm{CH}_{2}\right), 49.09\left(2 \times \mathrm{CH}_{2}\right), 48.75\left(\mathrm{CH}_{2}\right), 43.71(2 \times$ $\left.\mathrm{CH}_{2}\right), 41.36(\mathrm{C}), 35.86(\mathrm{C}), 27.69\left(4 \times \mathrm{CH}_{3}\right), 27.61\left(3 \times \mathrm{CH}_{3}\right), 27.13\left(3 \times \mathrm{CH}_{3}\right), 26.89\left(3 \times \mathrm{CH}_{3}\right)$, $26.06\left(2 \times \mathrm{CH}_{2}\right), 24.08\left(2 \times \mathrm{CH}_{2}\right), 22.45\left(2 \times \mathrm{CH}_{2}\right), 21.35\left(\mathrm{CH}_{2}\right) ;$ FAB-MS: $\mathrm{C}_{69} \mathrm{H}_{95} \mathrm{O}_{18} \mathrm{~N}_{4} \mathrm{~S}_{2} \mathrm{Na}$ $[\mathrm{M}+\mathrm{Na}]^{+}$, found $1354.6(17.5 \%)$, calculated 1354.6.

6- $\{N$-[4-[3-phenyloxyl-2-[2-[2-[3-[2-[1,3-dihydro-3,3-dimethyl-1-(4-sulfobutyl)]-2H-indol-2ylidene]-ethylidene]-1-cyclohexen-1-yl]-ethenyl]-3,3-dimethyl-1-(4-sulfobutyl)-3H-indolium hydroxide]-butyloxy]-( $N^{\prime}$-Boc)-amine\}-6-deoxy- $\beta$-D-glucosamine (2). Compound 14 (100 mg, 


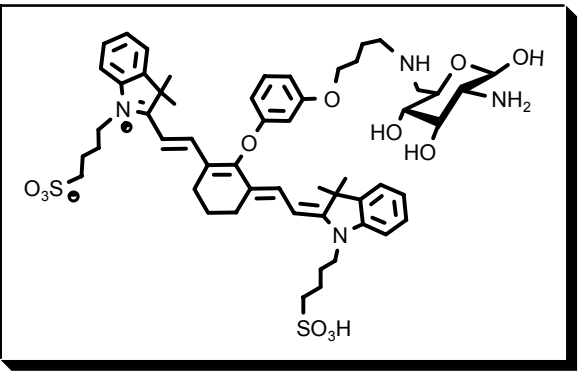

$0.074 \mathrm{mmol})$ was dissolved in a mixture $(6 \mathrm{~mL})$ of dichloromethane and trifluoacetic acid (1: 2, v/v). This solution was stirred at room temperature for about $5 \mathrm{~h}$. After removing the solvent, the residue was dissolved in $0.5 \mathrm{~mL}$ of methanol. Diethyl ether $(10 \mathrm{~mL})$ was added to this solution, and the final product $2(67 \mathrm{mg}, 0.065 \mathrm{mmol}$, $88 \%$ ) was collected after filtration as a dark green powder. ${ }^{1} \mathrm{H}$ NMR (400 $\left.\mathrm{MHz}, \mathrm{CD}_{3} \mathrm{OD}\right): \delta 7.38$ $7.24(\mathrm{~m}, 8 \mathrm{H}), 7.15(\mathrm{br}, 2 \mathrm{H}), 6.75(\mathrm{~d}, 2 \mathrm{H}, J=8.0 \mathrm{~Hz}), 6.58$ (d, 2H, $J=8.4 \mathrm{~Hz}), 6.51(\mathrm{br}, 2 \mathrm{H}), 5.39$ (d, $1 \mathrm{H}, J=3.6 \mathrm{~Hz}), 4.10-4.02(\mathrm{t}, 4 \mathrm{H}, J=8.8 \mathrm{~Hz}), 3.95(\mathrm{br}, 3 \mathrm{H}), 3.79(\mathrm{t}, 1 \mathrm{H}, J=8.8 \mathrm{~Hz}), 3.70$ (t, $1 \mathrm{H}, J=$ $10.4 \mathrm{~Hz}), 3.57$ (t, $1 \mathrm{H}, J=8.8 \mathrm{~Hz}), 3.42(\mathrm{~m}, 1 \mathrm{H}), 3.29-3.20(\mathrm{~m}, 2 \mathrm{H}), 3.15-3.05(\mathrm{~m}, 4 \mathrm{H}), 2.83(\mathrm{q}, 5 \mathrm{H}$, $J=6.4 \mathrm{~Hz}), 1.88$ (br, 14H), $1.30(\mathrm{~s}, 12 \mathrm{H}) ;{ }^{13} \mathrm{C}$ NMR $\left(100 \mathrm{MHz}, \mathrm{CD}_{3} \mathrm{OD}\right): 173.21(2 \times \mathrm{C}), 173.06(2$ $\times \mathrm{C}), 165.85(\mathrm{C}), 160.05(\mathrm{C}), 143.73(2 \times \mathrm{CH}), 142.44(\mathrm{C}), 142.22(2 \times \mathrm{CH}), 136.43(2 \times \mathrm{C}), 132.67$ $(\mathrm{CH}), 129.81(\mathrm{CH}), 125.90(2 \times \mathrm{C}), 123.87(\mathrm{CH}), 123.36(\mathrm{CH}), 116.15(2 \times \mathrm{CH}), 111.89(2 \times \mathrm{CH})$, $108.34(2 \times \mathrm{CH}), 100.57(2 \times \mathrm{CH}), 95.77(\mathrm{CH}), 73.13(\mathrm{CH}), 72.03(\mathrm{CH}), 70.05(\mathrm{CH}), 69.12\left(\mathrm{CH}_{2}\right)$, $57.79(\mathrm{CH}), 54.38(\mathrm{CH}), 51.89\left(2 \times \mathrm{CH}_{2}\right), 50.15\left(2 \times \mathrm{CH}_{2}\right), 44.85\left(2 \times \mathrm{CH}_{2}\right), 41.80\left(\mathrm{CH}_{2}\right), 33.21(2$ $\times \mathrm{C}), 28.67\left(2 \times \mathrm{CH}_{3}\right), 27.16\left(2 \times \mathrm{CH}_{2}\right), 25.27\left(2 \times \mathrm{CH}_{2}\right), 23.58\left(2 \times \mathrm{CH}_{3}\right), 22.47\left(\mathrm{CH}_{2}\right), 21.95$ $\left(\mathrm{CH}_{2}\right), 21.13\left(\mathrm{CH}_{2}\right)$; HRFAB-MS: $\mathrm{C}_{54} \mathrm{H}_{72} \mathrm{O}_{12} \mathrm{~N}_{4} \mathrm{~S}_{2}[\mathrm{M}]^{+}$, found 1032.4588 (13.1\%), calculated 1032.4553 .

\section{Preparation of control molecule 15}
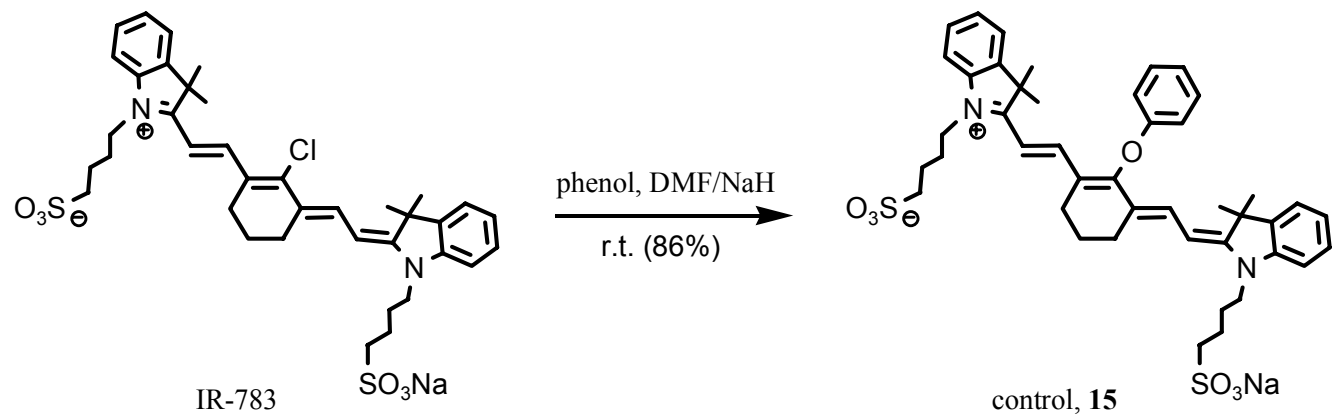

Scheme S1. Synthetic procedure for control molecule 15. 
2-[2-[2-phenyloxyl-[3-[2-[1,3-dihydro-3,3-dimethyl-1-(4-sulfobutyl)]-2H-indol-2-ylidene]ethylidene]-1-cyclohexen-1-yl]-ethenyl]-3,3-dimethyl-1-(4-sulfobutyl)-3H-indolium hydroxide (control, 15). Control molecule 15 was prepared according to scheme $\mathrm{S} 1 . \mathrm{NaH}$ ( $60 \%$ in mineral oil)

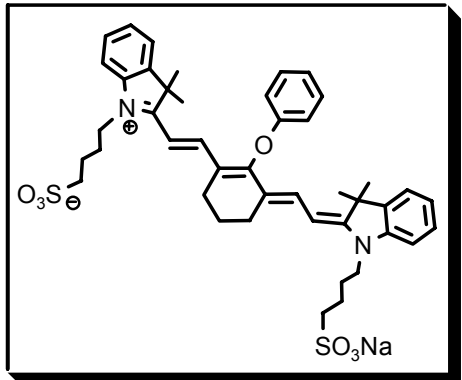

(15 mg, $0.38 \mathrm{mmol}, 1.2$ equiv.) was added to a solution of phenol (30 $\mathrm{mg}, 0.32 \mathrm{mmol}$ ) in $5 \mathrm{~mL}$ of anhydrous DMF. This mixture was stirred at room temperature for about 15 minutes. IR-783 (168 mg, 0.22 mmol, 0.7 equiv.) dissolved in $0.5 \mathrm{~mL}$ DMF was added dropwise to this mixture. The reaction mixture was stirred for another 20 min at room temperature, and a small piece of dry ice was used to quench the reaction. DMF was evaporated under vacuum at $50^{\circ} \mathrm{C}$. The crude product was purified by column chromatography (acetonitrile/ $\mathrm{H}_{2} \mathrm{O}=100 / 10, \mathrm{v} / \mathrm{v}$ ) to give control molecule 15 as deep green solid (47 mg, $0.035 \mathrm{mmol}$, yield: 74\%). ${ }^{1} \mathrm{H}$ NMR (400 $\left.\mathrm{MHz}, \mathrm{CD}_{3} \mathrm{OD}\right): \delta 7.94(\mathrm{~d}, 2 \mathrm{H}, J=14.0 \mathrm{~Hz}), 7.40-7.34(\mathrm{~m}, 6 \mathrm{H}), 7.30(\mathrm{t}, 2 \mathrm{H}, J=8.4 \mathrm{~Hz}), 7.17(\mathrm{t}, 2 \mathrm{H}$, $J=7.2 \mathrm{~Hz}), 7.10(\mathrm{~d}, 2 \mathrm{H}, J=8.0 \mathrm{~Hz}), 7.02(\mathrm{t}, 1 \mathrm{H}, J=8.2 \mathrm{~Hz}), 6.18(\mathrm{~d}, 2 \mathrm{H}, J=14.4 \mathrm{~Hz}), 4.13(\mathrm{br}$, 4H), $2.90(\mathrm{br}, 4 \mathrm{H}), 2.75(\mathrm{br}, 4 \mathrm{H}), 1.97(\mathrm{br}, 10 \mathrm{H}), 1.28(\mathrm{~s}, 12 \mathrm{H}) ;{ }^{13} \mathrm{C}$ NMR $\left(100 \mathrm{MHz}, \mathrm{CD}_{3} \mathrm{OD}\right)$ : $173.25(2 \times \mathrm{C}), 164.91(\mathrm{C}), 161.11(2 \times \mathrm{CH}), 143.36(2 \times \mathrm{CH}), 143.07(2 \times \mathrm{C}), 142.25(2 \times \mathrm{CH})$, $131.36(2 \times \mathrm{CH}), 129.73(2 \times \mathrm{C}), 126.05(2 \times \mathrm{C}), 123.51(\mathrm{C}), 123.32(2 \times \mathrm{CH}), 123.24(\mathrm{CH}), 115.64$ $(2 \times \mathrm{CH}), 112.00(2 \times \mathrm{CH}), 101.09(2 \times \mathrm{CH}), 51.69\left(2 \times \mathrm{CH}_{2}\right), 50.04\left(2 \times \mathrm{CH}_{2}\right), 44.77(2 \times \mathrm{C}), 28.11$ $\left(4 \times \mathrm{CH}_{3}\right), 27.11\left(2 \times \mathrm{CH}_{2}\right), 25.09\left(2 \times \mathrm{CH}_{2}\right), 23.47\left(2 \times \mathrm{CH}_{3}\right), 22.34\left(\mathrm{CH}_{2}\right) ;$ HRFAB-MS: $\mathrm{C}_{44} \mathrm{H}_{52} \mathrm{O}_{7} \mathrm{~N}_{2} \mathrm{~S}_{2} \mathrm{Na}[\mathrm{M}+\mathrm{H}]^{+}$, found $807.3130(72 \%)$, calculated 807.3114 . 


\section{Analytical HPLC analysis.}
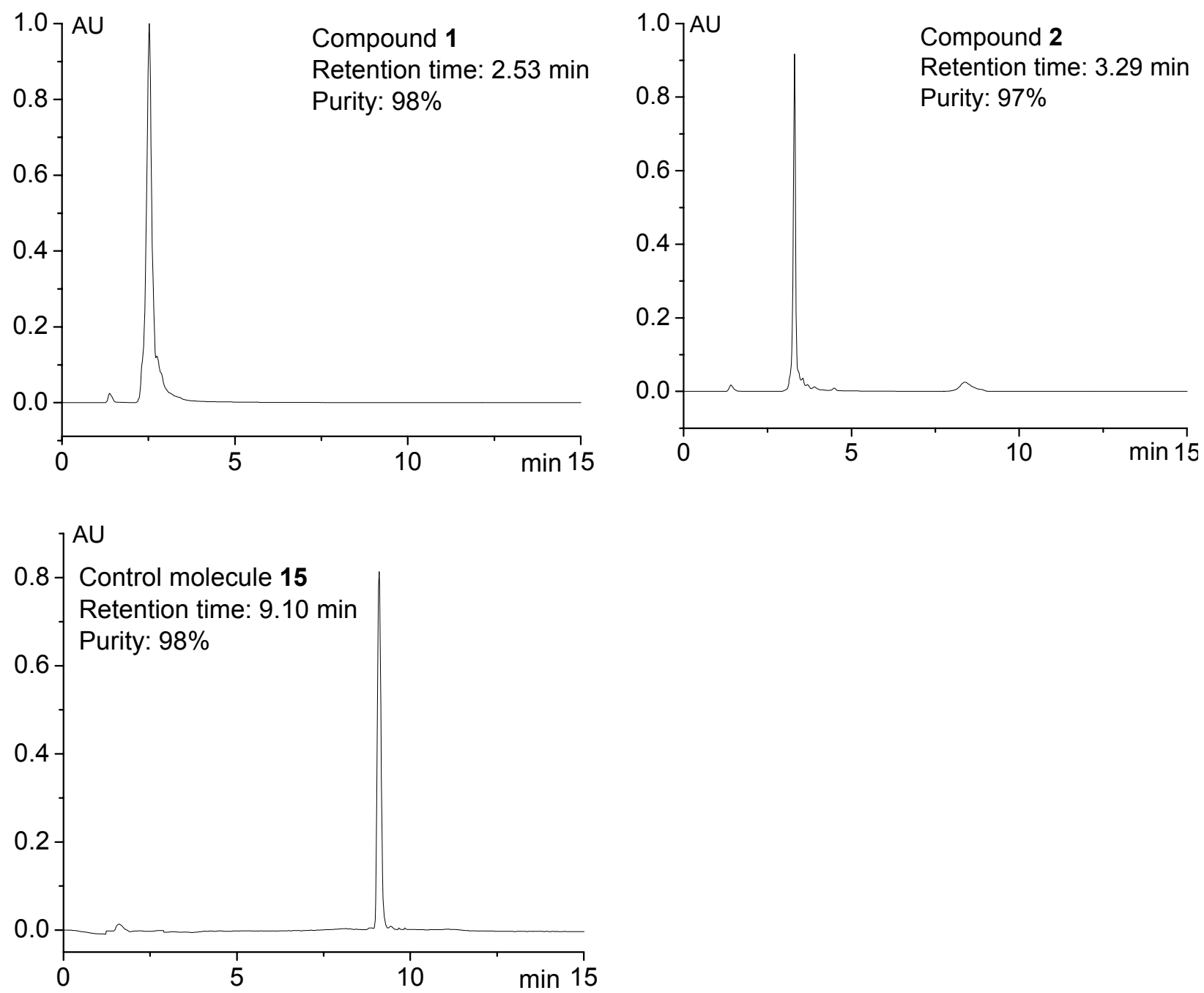

Figure S1. Analytical HPLC-Vis chromatography of compound 1, 2 and control molecule 15. Flow rate, $1.0 \mathrm{~mL} / \mathrm{min}$; solution A: 1000:1 $\mathrm{H}_{2} \mathrm{O} / \mathrm{TFA}$, solution $\mathrm{B}:$ 9:1:0.01 $\mathrm{CH}_{3} \mathrm{CN} / \mathrm{H}_{2} \mathrm{O} / \mathrm{TFA}$. 0-30 min: isocratic elution of 55:45 A/B; monitored at $700 \mathrm{~nm}$. 


\section{Photospectroscopic analysis.}

All spectra were recorded in a quartz cuvette $(10 \times 10 \mathrm{~mm})$ at $25^{\circ} \mathrm{C}$. Stock solutions of compound 1, 2, control molecule 15, and ICG were prepared and equilibrated at $25{ }^{\circ} \mathrm{C}$ for $14 \mathrm{~h}$. Solutions of each compound were prepared at different concentrations $(0.5-5.0 \mu \mathrm{M})$ by diluting these stock solutions with phosphate buffered saline (PBS) $(\mathrm{pH}=7.4)$. Maximum absorbance wavelength and corresponding molar extinction coefficient were determined for each compound. Fluorescence emission spectra of all samples $(0.1-1.0 \mathrm{uM})$ were collected at a 90-degree angle relative to the excitation light path.
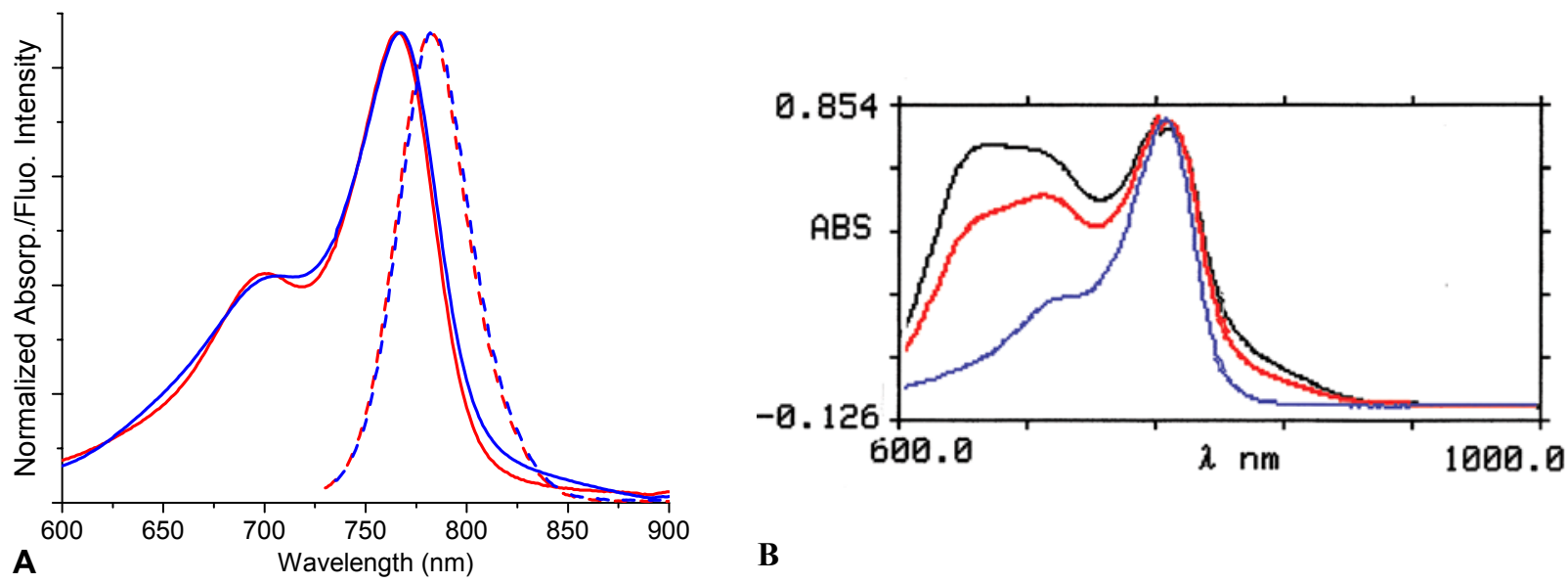

Figure S2. (A) Normalized absorption and fluorescence spectra of 1 and $\mathbf{2}$ (excited at 766 and 768 $\mathrm{nm}$, respectively) in PBS buffer ( $\mathrm{pH}$ 7.4). Absorption (solid red line) and emission (dashed red line) spectra of 1; absorption (solid blue line) and emission (dashed blue line) spectra of 2. (B) Normalized absorption spectra of control molecule $\mathbf{1 5}$ in PBS, pH 7.4 at concentrations of $2.0 \mathrm{uM}$ (blue line), $8.0 \mathrm{uM}$ (red line), and $15 \mathrm{uM}$ (black line). 
Quantum yield measurements: We determined the fluorescence quantum yield according to established techniques, ${ }^{3}$ which measure the efficiency of photon energy transfer. The fluorescence quantum yields of compound 1, 2, IR-783, and ICG in PBS pH $=7.4$ were referenced to ICG in DMSO (Q. Y. = 0.13). The absorbance of five serial dilutions of each compound was measured in the concentration range between $0.1-1.0 \mathrm{uM}$, which were chosen such as to fall within an absorbance range between 0 to 0.1 when excited at the optimal excitation wavelength. The fluorescence intensity of each fully corrected fluorescence spectrum was integrated. The integrated fluorescence intensity was plotted against the absorbance maximum (Figure S3), and fitted with a straight line. The quantum yield was determined according to Equation 1:

$$
\phi_{S}=\phi_{r}\left(\frac{\operatorname{Grad}_{s}}{\operatorname{Grad}_{r}}\right)\left(\frac{\eta_{s}^{2}}{\eta_{r}^{2}}\right)\left(\frac{q_{s}}{q_{r}}\right) \quad \text { Equation } 1
$$

In Equation 1, subscripts $\mathrm{s}$ and $\mathrm{r}$ refer to sample and reference, respectively. $\phi$ represents the fluorescence quantum yield. Grad represents the gradient from the plot of integrated fluorescence intensity $v s$ absorbance. $\eta$ represents the refractive index of the solvent, and $\mathrm{q}$ represents a correction factor accounting for the excitation wavelength used. We assumed $q_{\mathrm{s}} / q_{\mathrm{r}}$ to be 1 since all spectra were recorded with very similar excitation wavelengths $\lambda_{\text {exc. }}$ This method typically provides an estimate of the fluorescence quantum yield lying within an error of $10 \%$. 

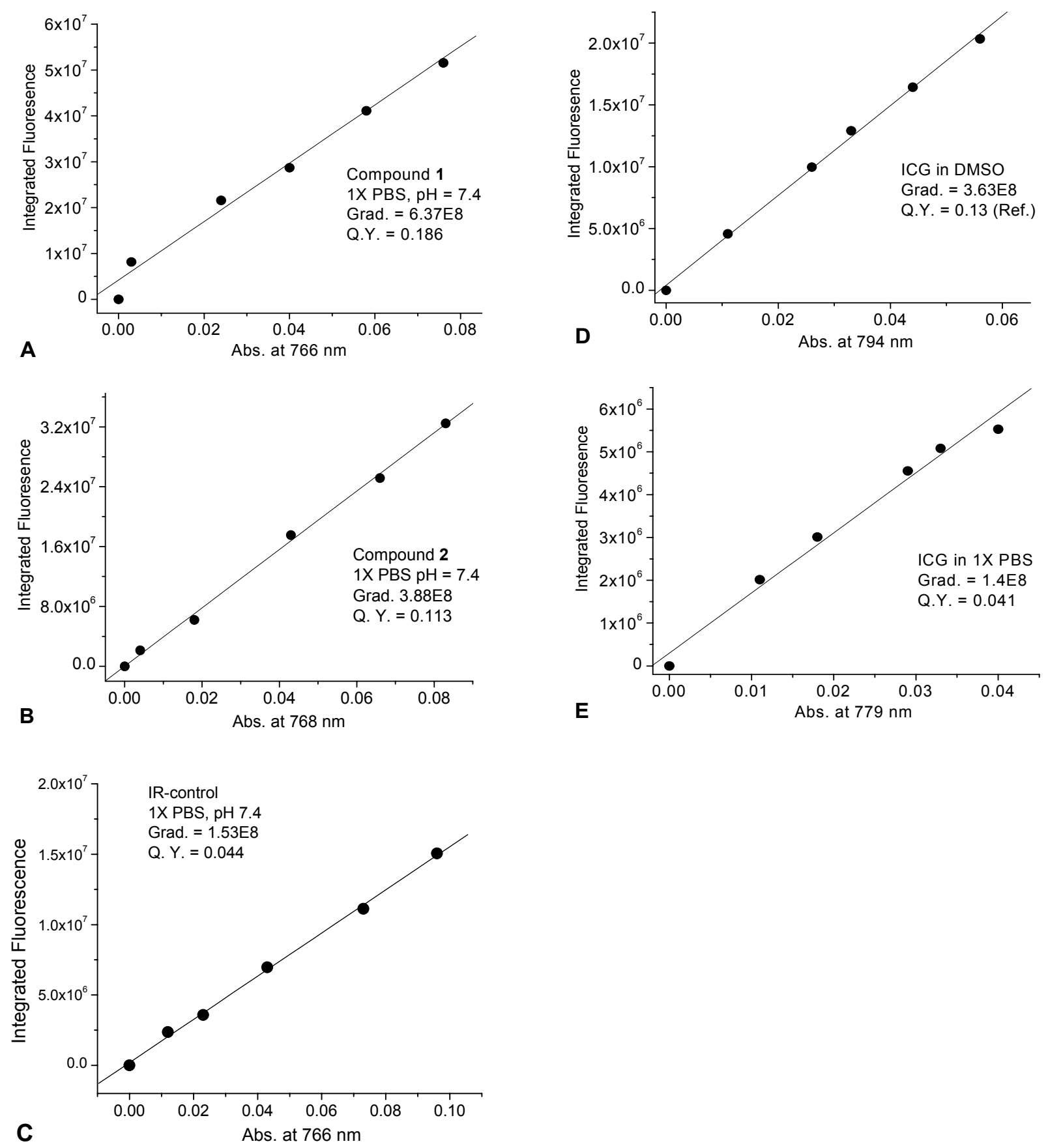

Figure S3. Integrated fluorescence vs. absorbance plots used to determine relative quantum yields of compound 1 (A), 2 (B), control molecule 15 (C), and ICG (D) in PBS, pH 7.4 compared with ICG in DMSO (E, ref). 
pH Dependence of fluorescence intensity. $1.0 \mu \mathrm{L}$ of NIR dye stock solution $\left(1.0 \times 10^{-3} \mathrm{M}\right)$ in PBS (5\% methanol used as co-solvent) was added to $2.0 \mathrm{~mL}$ of $0.1 \mathrm{M}$ sodium phosphate solution in a 10 $\mathrm{mm} \times 10 \mathrm{~mm}$ quartz cuvette. $\mathrm{pH}$ values ranging from 1.01 to 12.57 were adjusted by means of 0.1 $\mathrm{M} \mathrm{HCl}$ and $\mathrm{NaOH}$. pH-dependent fluorescence emission intensity profiles of compound $\mathbf{1}, \mathbf{2}$ (see Figure S4), and 15 were obtained by monitoring fluorescence intensities for each $\mathrm{pH}$ value at 782, 784, and $783 \mathrm{~nm}$ (excited at 766, 768, and $766 \mathrm{~nm}$,), respectively. Excitation and emission slits were set to $4.0 \mathrm{~nm}$. Average fluorescence emission intensity values were obtained from three independent measurements.
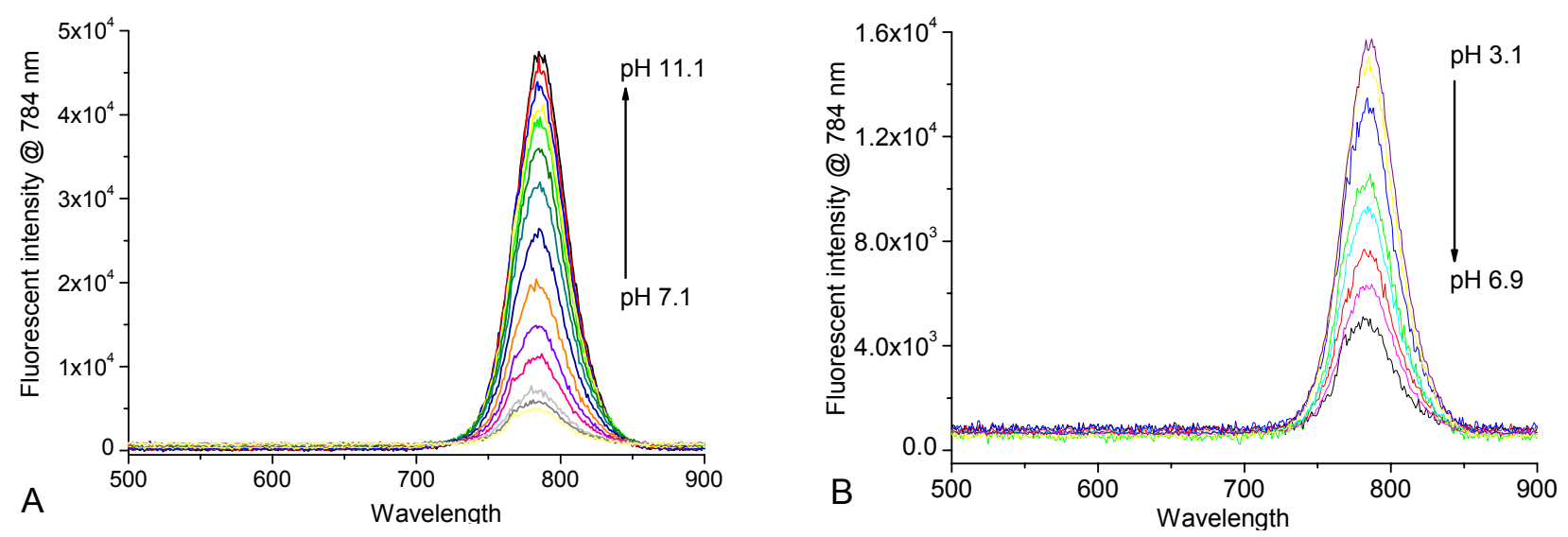

Figure S4. Fluorescence intensity of compound $2(1.0 \mathrm{uM}$, excited at $768 \mathrm{~nm}$, slit $=4,298 \mathrm{~K})$ as a function of $\mathrm{pH}$ in $\mathrm{PBS}(\mathrm{pH}$ 7.4). (A) fluorescence intensity of $\mathbf{2}$ increases with increasing $\mathrm{pH}$ value ( $\mathrm{pH}$ range 6.9-11.1); (B) fluorescence intensity of 2 decreases with increasing $\mathrm{pH}$ value $(\mathrm{pH}$ range 3.1-6.9.

\section{Cell culture:}

Four human mammary epithelial cell (HMEC) lines representing different stages of malignancy were obtained from the American Type Culture Collection (ATCC, Rockville, MD). MCF-12A, a spontaneously immortalized nonmalignant cell line established from MCF-12M mortal cells, was cultured in DMEM-Ham's F12 medium (Invitrogen, Carlsbad, CA) ${ }^{4}$. MCF-7, an estrogen-sensitive 
weakly metastatic breast cancer cell line, was cultured in EMEM medium (Mediatech, Herndon, VA) supplemented with $10 \%$ fetal bovine serum and antibiotics ${ }^{5}$. The invasive and metastatic HMEC lines MDA-MB-231 and MDA-MB-435 were maintained in RPMI-1640 medium (Invitrogen) supplemented with $10 \%$ fetal bovine serum, 100 units $/ \mathrm{mL}$ penicillin, and $100 \mathrm{~g} / \mathrm{mL}$ streptomycin (Invitrogen, Carlsbad, CA). MCF-7, MDA-MB-231, and MDA-MB-435 cells were originally isolated from pleural effusions of patients with breast cancer. All cells were grown as monolayers in $75 \mathrm{~cm}^{2}$ culture flasks in a humidified atmosphere of $5 \% \mathrm{CO}_{2}$ in air at $37^{\circ} \mathrm{C}$, and were harvested when they reached $80 \%$ confluence to maintain exponential growth.

\section{MTT cell proliferation assay:}

An MTT cell proliferation assay was utilized to measure cell proliferation following exposure of cells to compound $\mathbf{1}, \mathbf{2}$, and $\mathbf{1 5}$. This MTT assay determines the ability of viable cells to reduce yellow [3-(4,5-dimethylthiazol-2-yl)-2,5-diphenyltetrazolium bromide] (MTT) to blue-colored formazan crystals by mitochondrial enzymes. The concentration of formazan crystals dissolved in an organic solvent can be determined spectrophotometrically. An exponentially growing cell monolayer was harvested using $0.25 \%$ trypsin, and a single-cell suspension was obtained. Cells were counted using a hemacytometer and a light microscope (OLYMPUS BH-2, Center Valley, PA). Cell numbers of MCF-12A, MCF-7, MDA-MB-231, and MDA-MB-435 cells were optimized such that exponential growth was maintained throughout the entire duration of an MTT assay experiment. To this end, single cell suspensions of each cell line containing cell densities ranging from $5 \times 10^{2}$ to $1 \times 10^{6}$ cells/well in $100 \mu \mathrm{L}$ of cell culture medium were added to 96 -well plates. Eight replicates were prepared for each cell density. Following attachment of the cells, plates were incubated for 24 hours at $37^{\circ} \mathrm{C}$ in $5 \% \mathrm{CO}_{2}$. Cell culture media were exchanged for $100 \mu \mathrm{L}$ of phenol-red free 
medium per well. Ten $\mu \mathrm{L}$ of MTT (ATCC, Manassas, VA) was added to each well, and the plate was incubated for $3-4 \mathrm{~h}$ at $37^{\circ} \mathrm{C}$ in $5 \% \mathrm{CO}_{2}$. Clearly visible purple precipitate from formazan crystals was dissolved using $100 \mu \mathrm{L}$ of detergent reagent. The 96-well plates were kept in the dark overnight at room temperature, and a microplate reader (OPSYS MR, Dynex tech. West Sussex, UK) was used to detect the absorbance in each well at $570 \mathrm{~nm}$ and $650 \mathrm{~nm}$. Values from eight replicates were averaged. The absorbance difference between $570 \mathrm{~nm}$ and $650 \mathrm{~nm}$ was plotted against the number of cells $/ \mathrm{mL}$. The starting cell density was chosen to lie within the linear portion of this plot and an absorbance range of $0.75-1.25$. Starting cell numbers were optimal at $4.0 \times 10^{4}$ cells/well for MDA-MB-231 and MDA-MB-435 cells, and $3.0 \times 10^{4}$ cells/well for MCF-7 and MCF-12A cells, as determined from the linear correlation between the number of seeded cells and the optical density values (Figure S5).

This MTT assay was used to measure the cytotoxicity of compound $\mathbf{1}, \mathbf{2}$, and $\mathbf{1 5}$. The four HMEC lines (MCF-12A, MCF-7, MDA-MB-231, and MDA-MB-435) were trypsinized and transferred into a 96-well plate at optimal cell density (see above). After the cells attached to the 96-well plates, which typically required 12 to $24 \mathrm{~h}$, cell culture media were exchanged for corresponding cell culture media containing serial dilutions of compound $\mathbf{1}, \mathbf{2}$, or $\mathbf{1 5}$, which had been sterile filtered through MILLEX ${ }^{\circledR}$-HV $0.45 \mu \mathrm{m}$ syringe filter (Millipore Corp. Bedford, MA). The final concentrations of each compound were $0.0625 \mathrm{mM}, 0.1250 \mathrm{mM}, 0.2500 \mathrm{mM}, 0.5000 \mathrm{mM}, 1.0000$ $\mathrm{mM}$, and $2.0000 \mathrm{mM}$. These plates were then incubated for 24 hours at $37^{\circ} \mathrm{C}$ in a humidified atmosphere of $5 \% \mathrm{CO}_{2}$. Incubation media were removed, and the cells were washed to remove residual NIR compounds. $100 \mu \mathrm{L}$ of fresh phenol-red free media and $10 \mu \mathrm{L}$ of MTT solution were added to each well. Following $4 \mathrm{~h}$ incubation, $100 \mu \mathrm{L}$ of detergent reagent was added, and the plates were placed in the dark at r.t. overnight. 

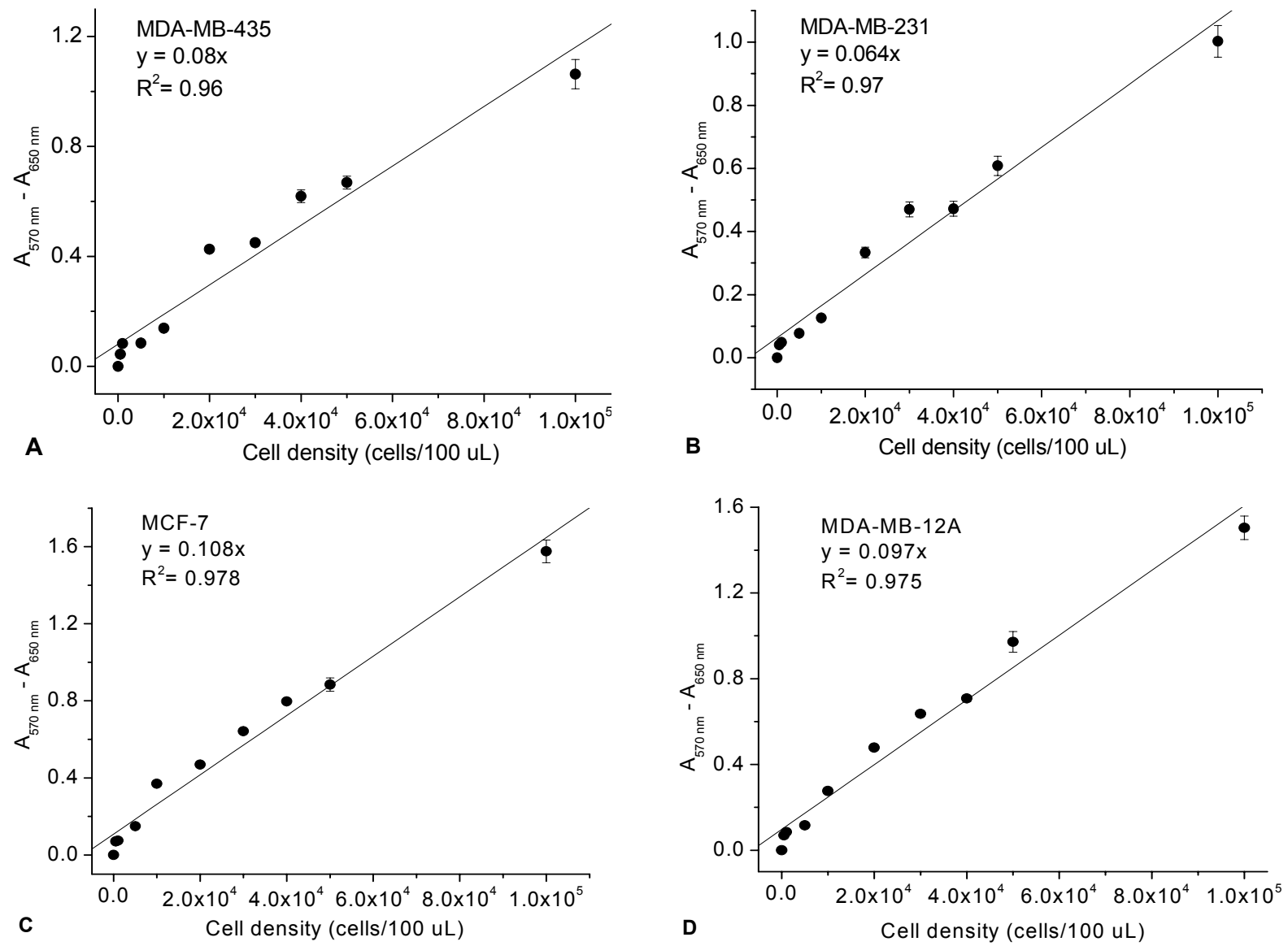

Figure S5. MTT standard curve of cell density $v_{s}$ optical density of formazan following a $24 \mathrm{~h}$ incubation, which was started after completion of cell attachment, with cell culture medium under control conditions: MDA-MB-435 (A), MDA-MB-231 (B), MCF-7 (C), and MDA-MB-12A (D). Linear correlations were obtained for all four cell lines in the range of 500-100,000 cells/well (100 $\mathrm{uL})$.

The MTT assay was finalized and absorbance measurements performed as described above. Experimental results represent cell viability $\left(V_{\mathrm{a}}\right)$ relative to respective control, which contained none of the above compounds. These results are expressed as $\%$ of control. $V_{\mathrm{a}}$ was calculated according to equation 2:

$$
V_{a}=\frac{A_{s-570}-A_{s-650}}{A_{o-570}-A_{o-650}} \times 100
$$

Equation 2

In equation $2, A_{s}$ represents the absorbance obtained from a cell sample incubated with a given NIR compound at a given concentration. $A_{o}$ represents the absorbance obtained from corresponding 
control cells incubated without any dye. The MTT assay results are presented as means \pm SD from eight replicates.

\section{Cellular uptake of NIR compounds by HMECs:}

MCF-12A, MCF-7, MDA-MB-231, or MDA-MB-435 HMECs were grown on glass chamber slides (Nalge Nunc, Naperville, IL) to $60 \%$ confluence. All four HMEC lines were incubated with $250 \mu \mathrm{M}$ of the NIR fluorescence probes $\mathbf{1}, \mathbf{2}$, or control molecule 15 for $24 \mathrm{~h}$. Cells were washed twice with PBS, pH 7.4 and fixed with 3\% paraformaldehyde in PBS for 20 min. Cells were washed three times with PBS, and cell nuclei were counterstained with a 1:3000 dilution of Hoechst H-33342 (Invitrogen-Molecular Probes, Eugene, OR) for $10 \mathrm{~min}$ at room temperature. Cells were washed, and a cover glass was attached with Faramount aqueous mounting medium (Dako, Carpinteria, CA). Microscopy was performed with an Olympus BX61 motorized upright microscope with epifluorescence and phase contrast optics using $10 \times / 0.3$ or $40 \times / 0.75$ lenses (Olympus Amercia Inc., Center Valley, PA) equipped with a Roper Photometrics CoolSnap HQ CCD camera (Photometrics, Tuson, AZ) and IPLab software (Scanalytics BD Biosciences, Rockville, MD) in the Johns Hopkins University School of Medicine Microscopy Facility (Director: Dr. Douglas B. Murphy). NIR fluorescence was measured using Indo-Cyanin Green filter cube C69785 with HQ775/50 exciter, HQ845/55 emitter, and Q810lp beamsplitter (Chroma Technology Corp., Rockingham, VT) . H33342 fluorescence was measured using the DAPI cube Semrock 5060B (Semrock, Rochester, NY). Phase contrast, NIR fluorescence, and H-33342 fluorescence images were acquired of the same field of view. NIR fluorescence was displayed in red, and H-33342 fluorescence was displayed in green, and both fluorescence images were superimposed. 


\section{Reference.}

1. Glunde, K.; Guggino, S. E.; Ichikawa, Y.; Bhujwalla, Z. M. Mol. Imaging 2003, 2, 24-36.

2. Suijkerbuijk, B. M. J. M.; Slagt, M. Q.; Klein Gebbink, R. J. M.; Lutz, M.; Spek, A. L.; van Koten, G. Tetrahedron Lett. 2002, 43, 6565-6568.

3. Mottram, L. F.; Boonyarattanakalin, S.; Kovel, R. E.; Peterson, B. R. Org. Lett. 2006, 8, 581-884.

4. Paine T. M.; Soule, H. D.; Pauley, R. J.; Dawson, P. J. Int. J. Cancer 1992, 50, 463-473.

5. Soule, H. D.; Vazguez, J.; Long, A.; Albert, S.; Brennan, M. J. Natl. Cancer Inst. 1973, 51, 14091416 

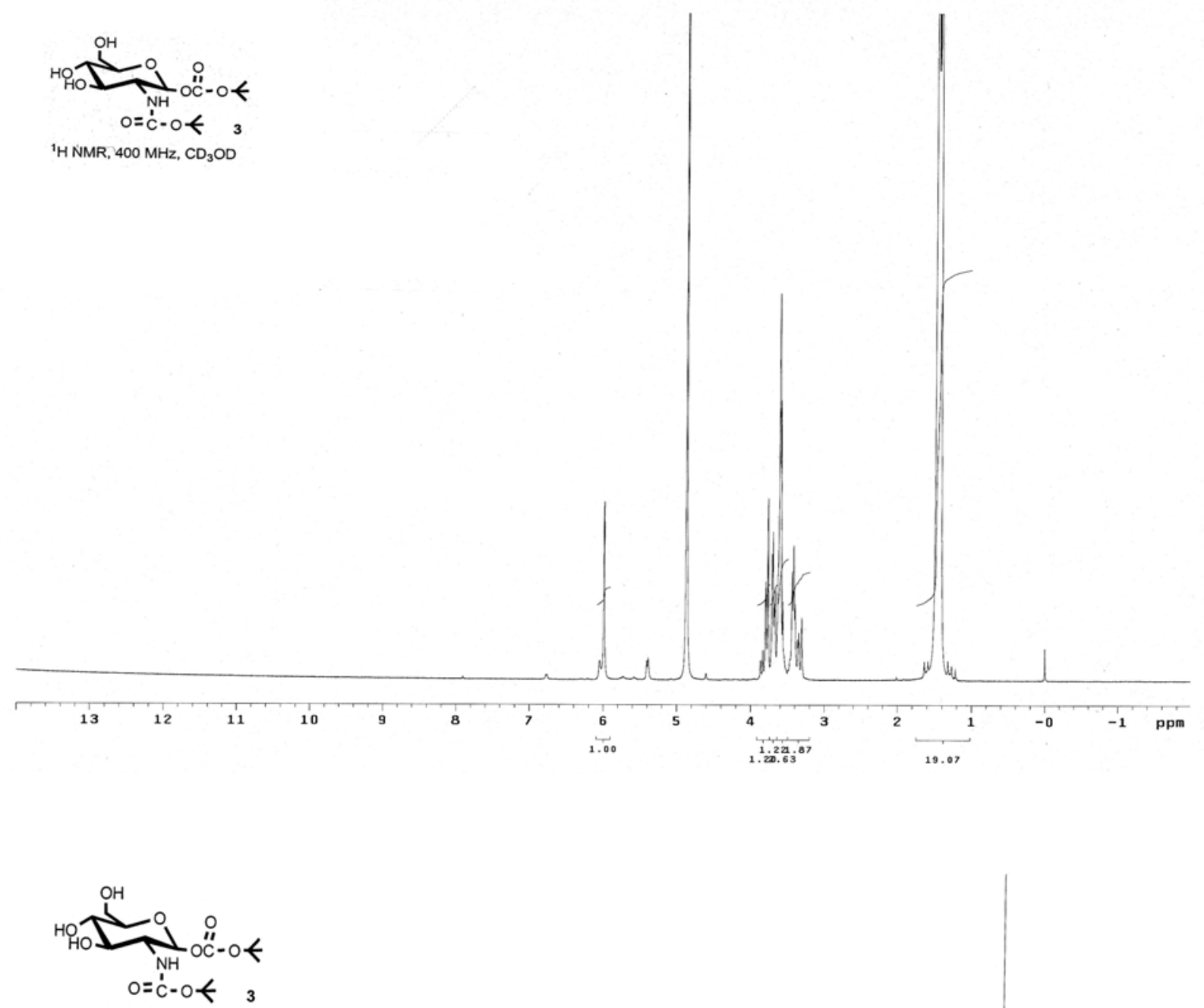

${ }^{13} \mathrm{C}$ NMR, $400 \mathrm{MHz}, \mathrm{CD}_{3} \mathrm{OD}$ 

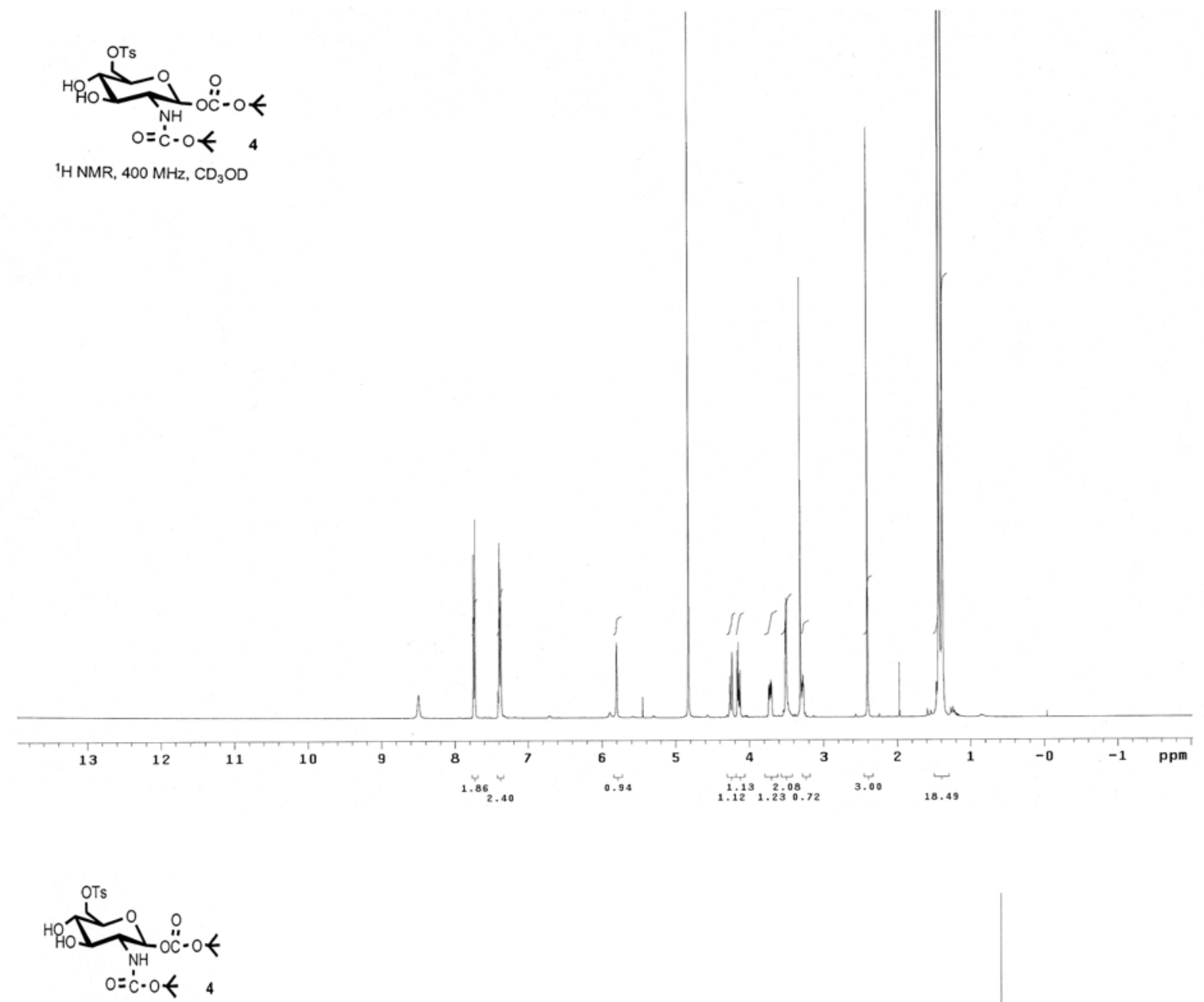

${ }^{13} \mathrm{C} \mathrm{NMR}, 400 \mathrm{MHz}, \mathrm{CD}_{3} \mathrm{OD}$

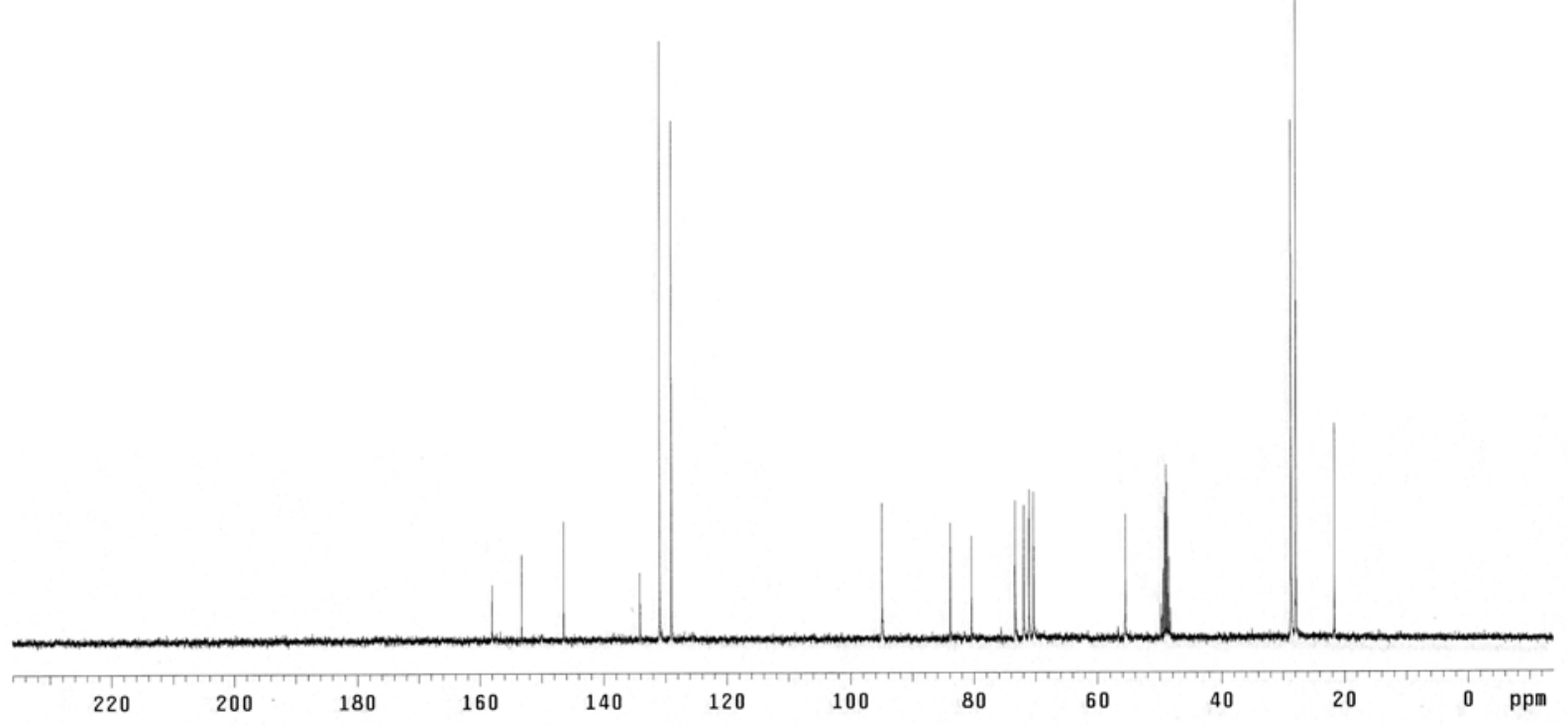



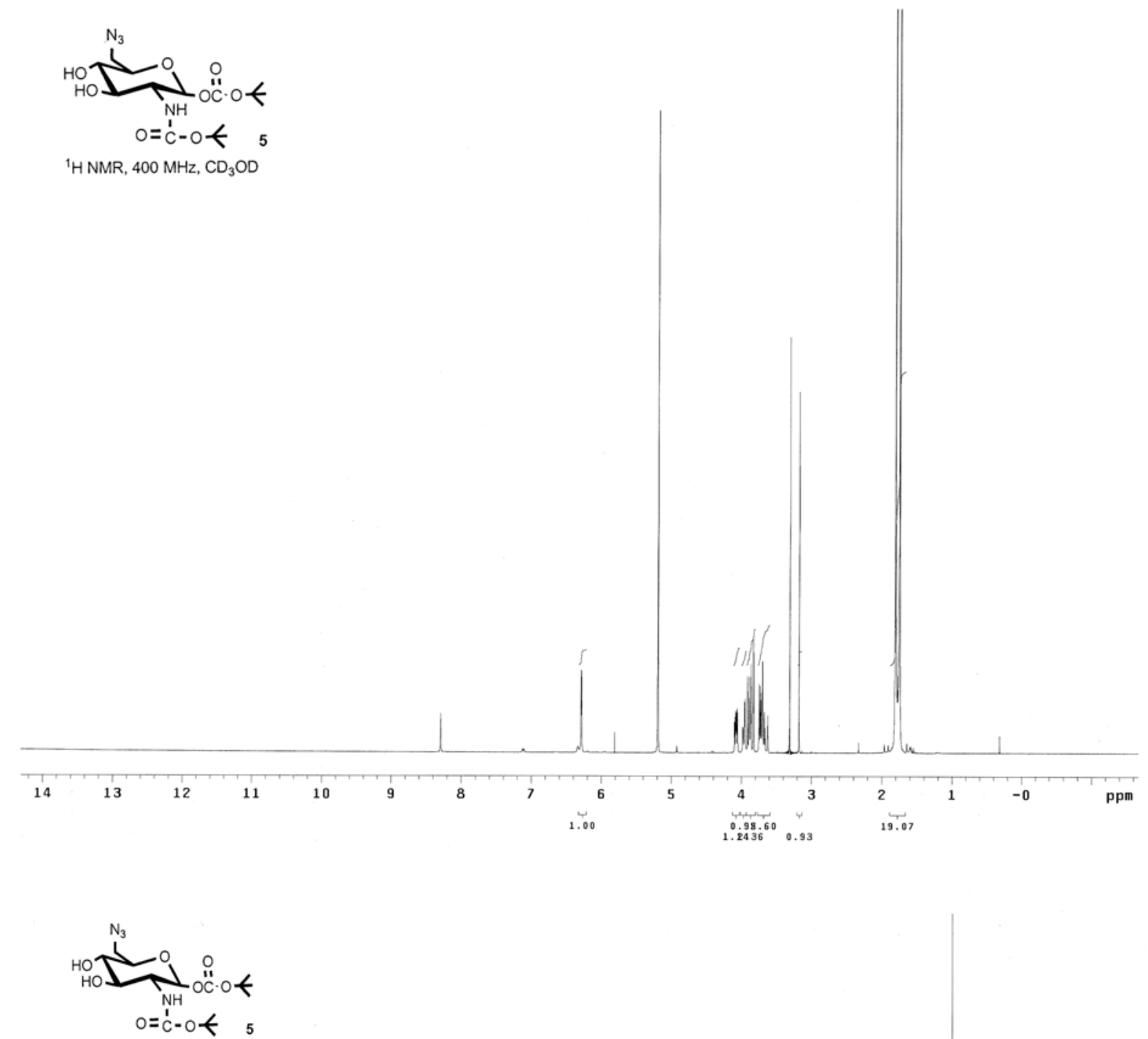

${ }^{13} \mathrm{C} \mathrm{NMR}, 400 \mathrm{MHz}, \mathrm{CD}_{3} \mathrm{OD}$ 

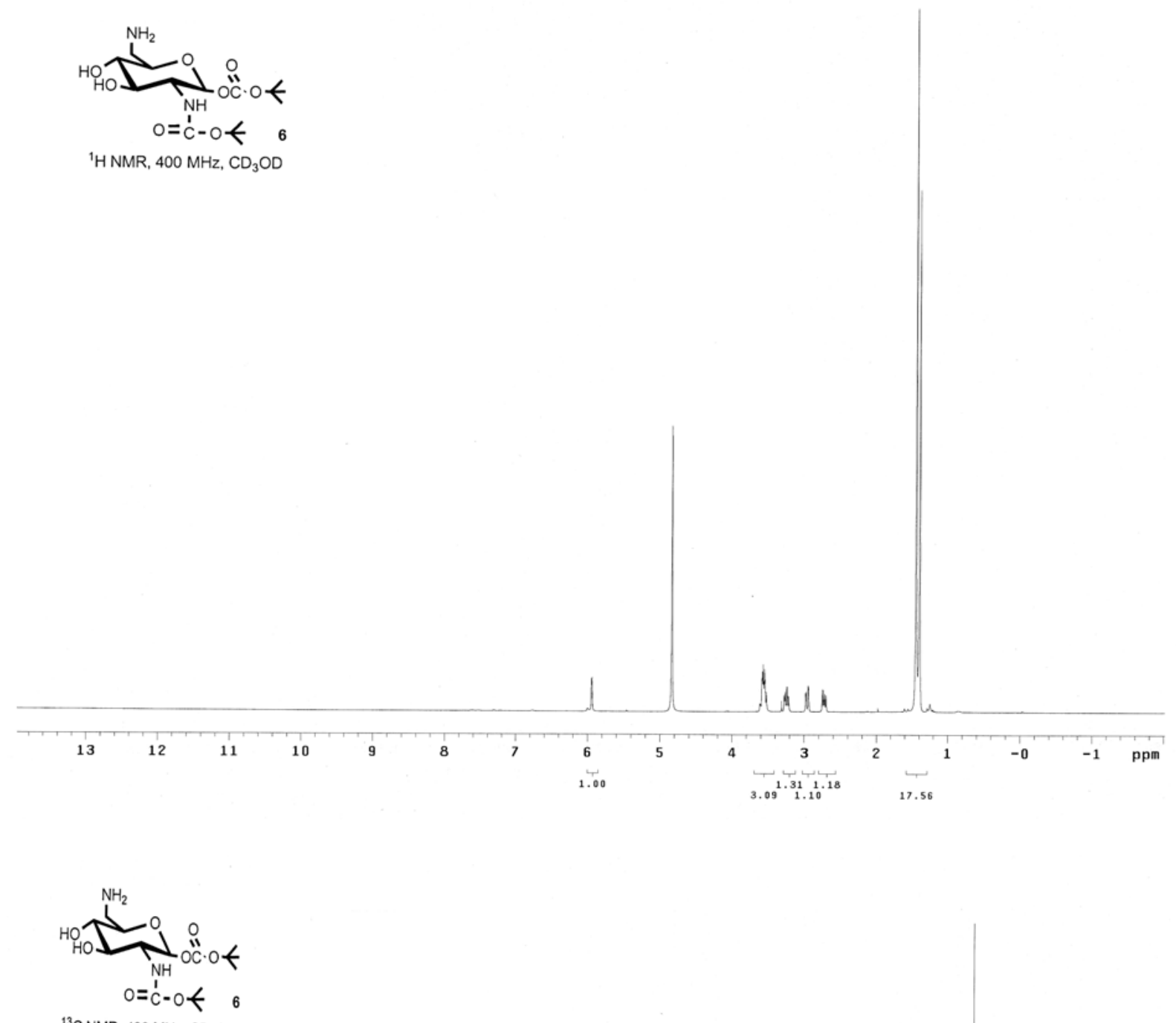

${ }^{13} \mathrm{CNMR}, 400 \mathrm{MHz}, \mathrm{CD}_{3} \mathrm{OD}$ 

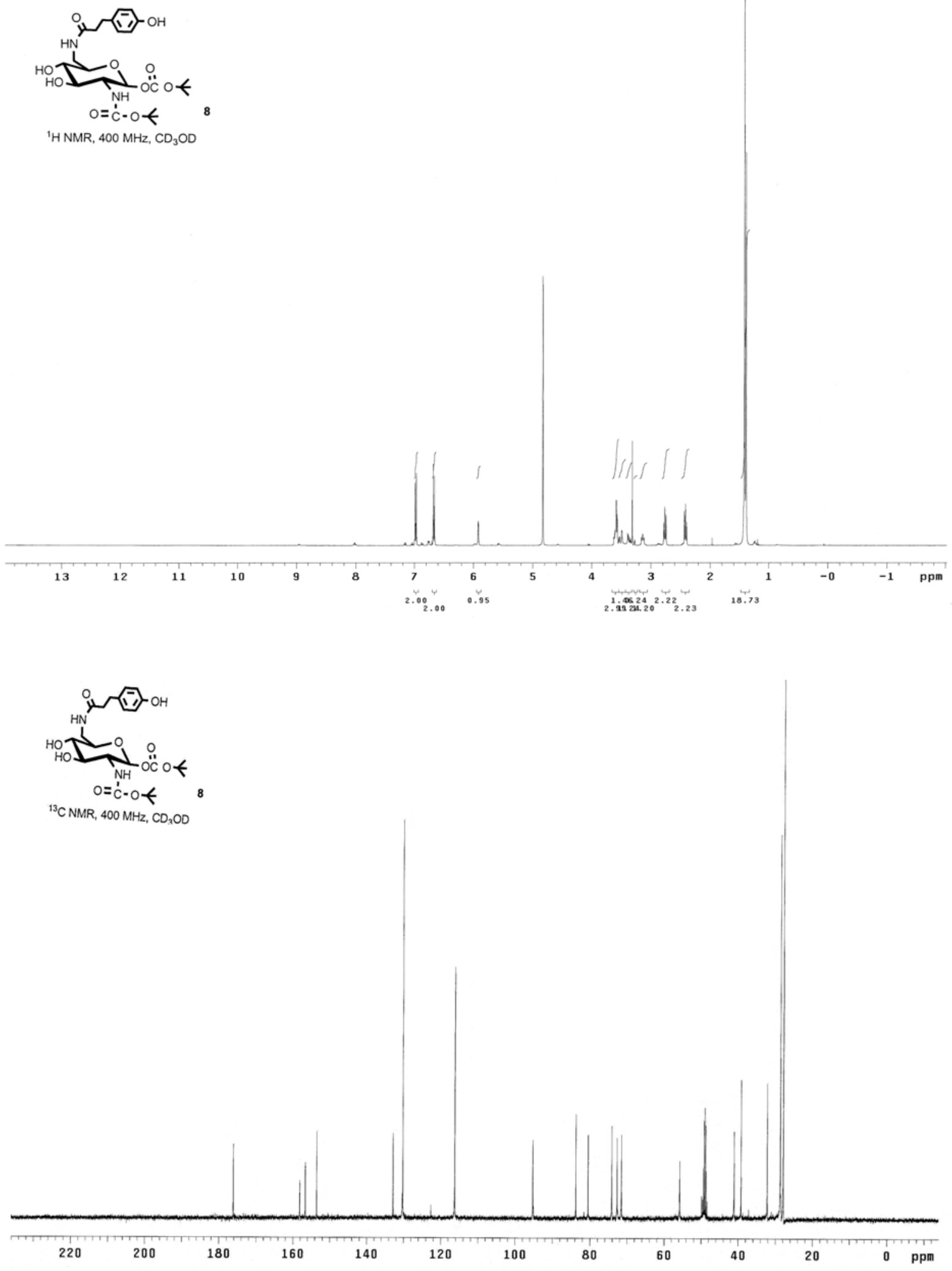

S26 

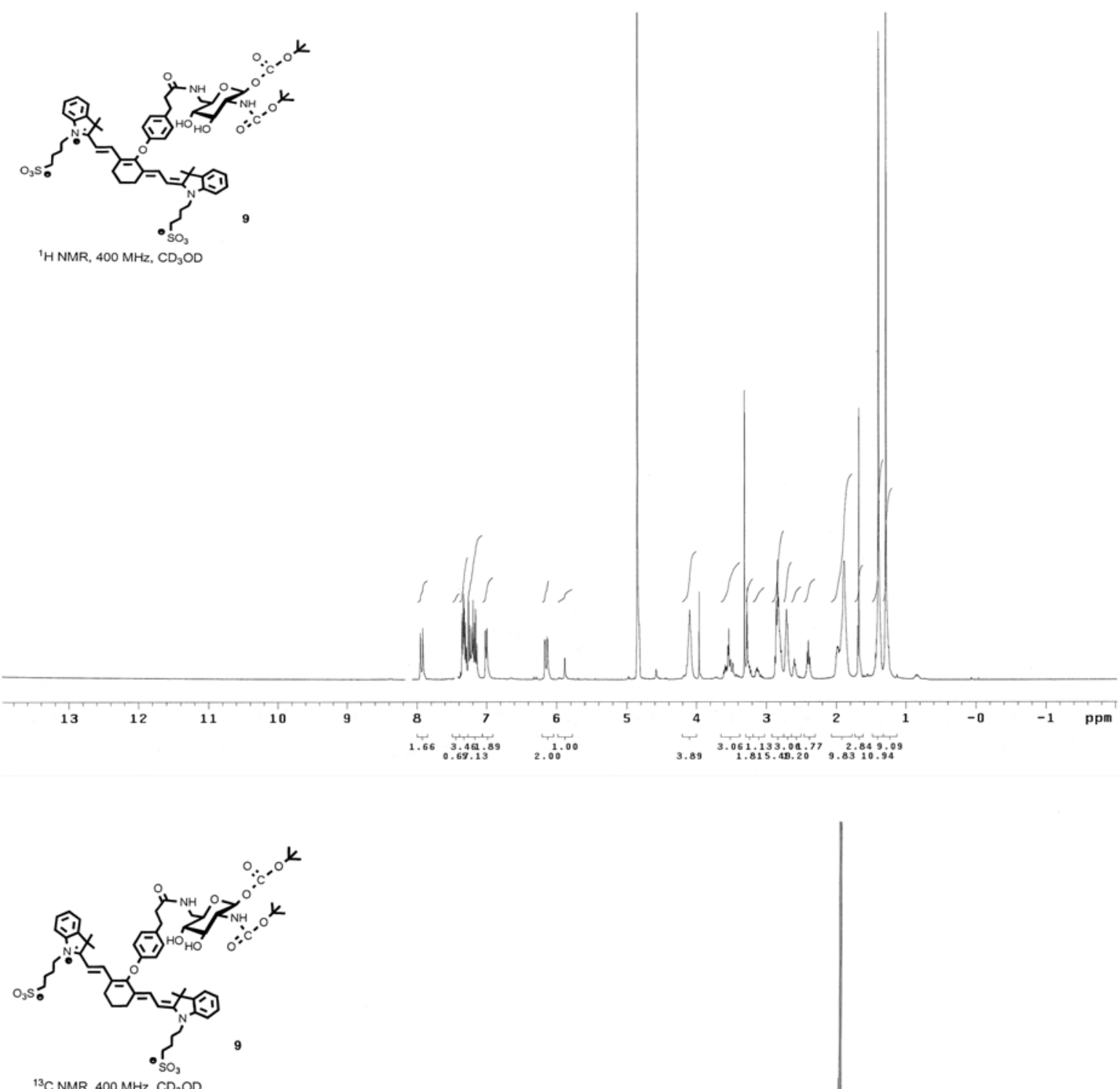

${ }^{13} \mathrm{C} \mathrm{NMR}, 400 \mathrm{MHz}, \mathrm{CD}_{3} \mathrm{OD}$

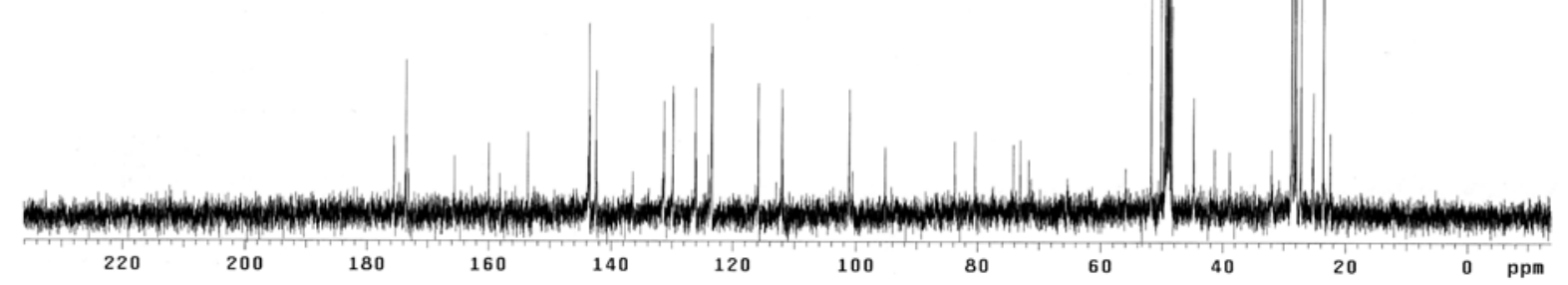



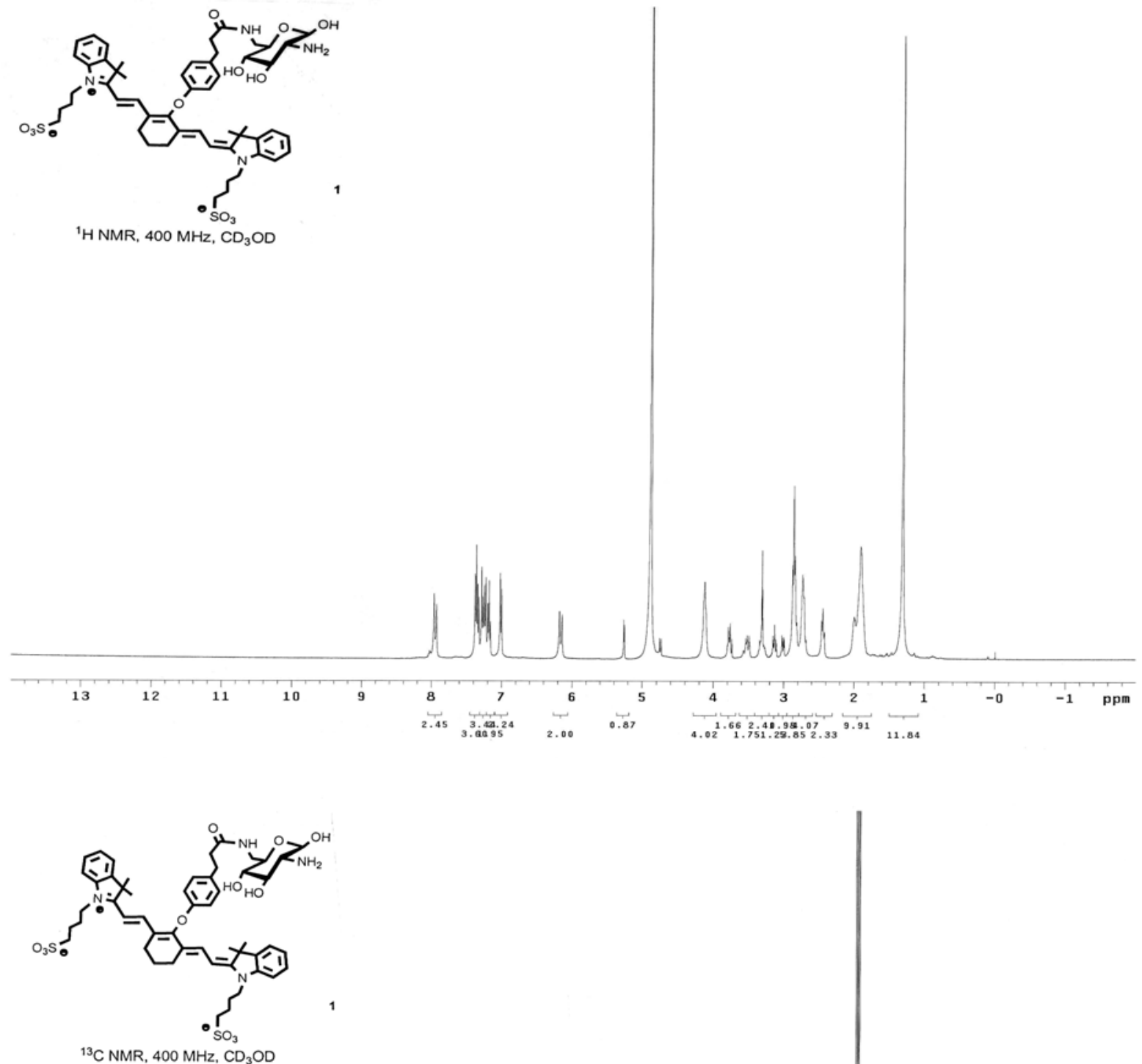

${ }^{13} \mathrm{C} \mathrm{NMR}, 400 \mathrm{MHz}, \mathrm{CD}_{3} \mathrm{OD}$

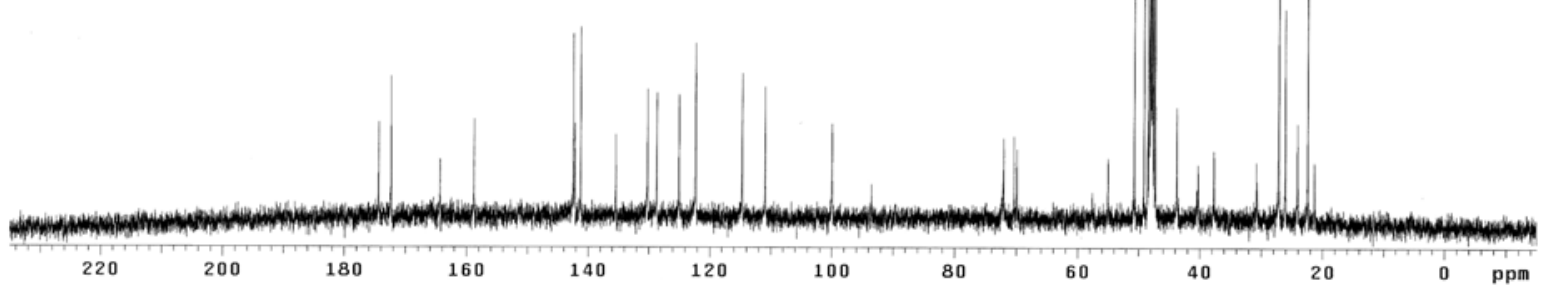

S28 
[ Mass Spectrum ]

Data : J5.1668-0D2

Sample: Glucosamıne-[R7g]

Date : 23-Sep-2085 14:19

Nate : in NBA

Inlet : Reserv. Ion Mode : FAB+

Spectrum Type : Normal Ion [MF-Linear]

RT : $0.19 \mathrm{~min}$

Scan\# : $(1,3)$
Int. : 19.78

Output $\mathrm{m} / \mathrm{z}$ range : 845.B235 ta 1080.7469 359043

Cut Level : $0.06 \%$
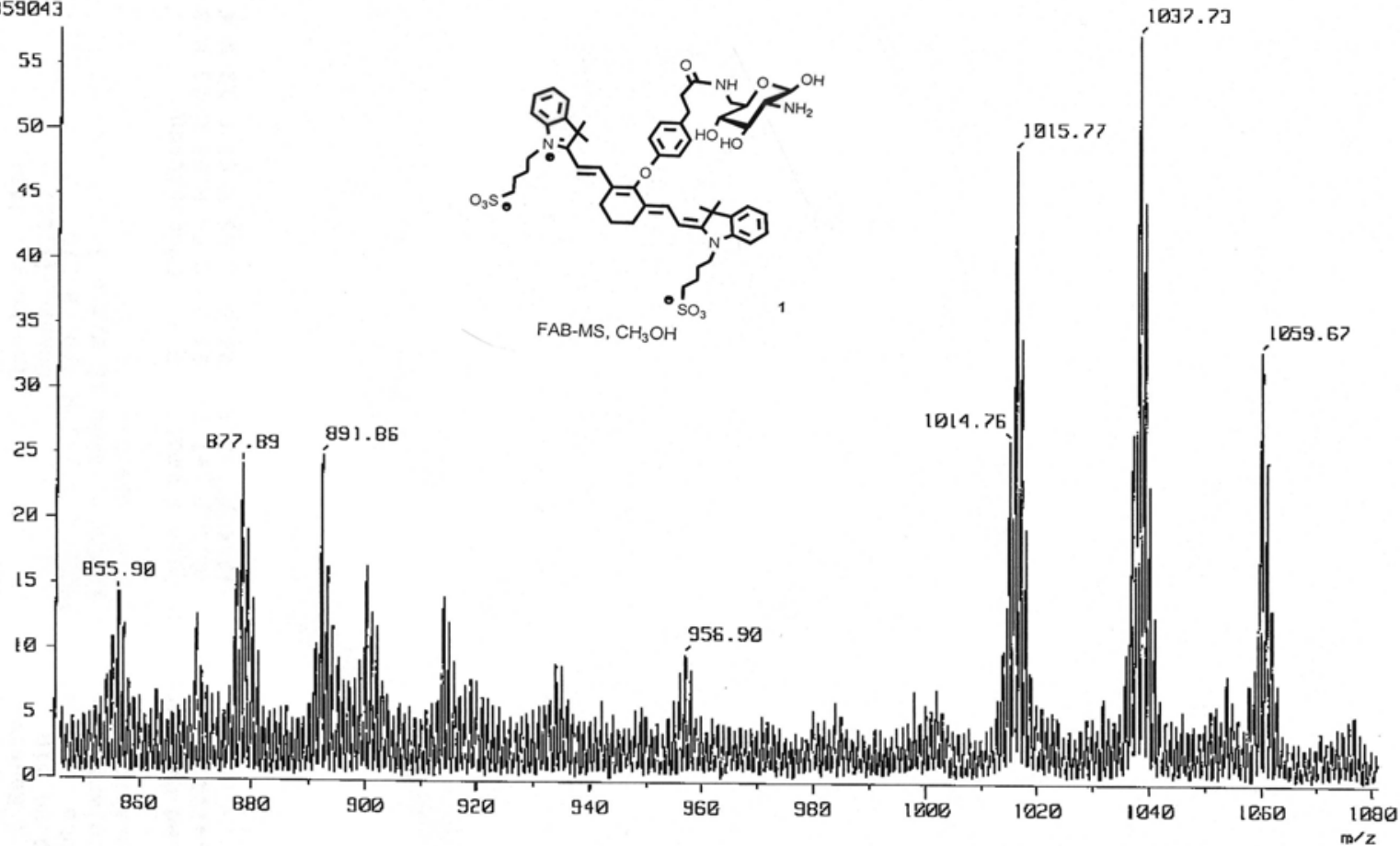
品会。我

' $\mathrm{H}$ NMR, $400 \mathrm{MHz}, \mathrm{CD}_{3} \mathrm{OD}$
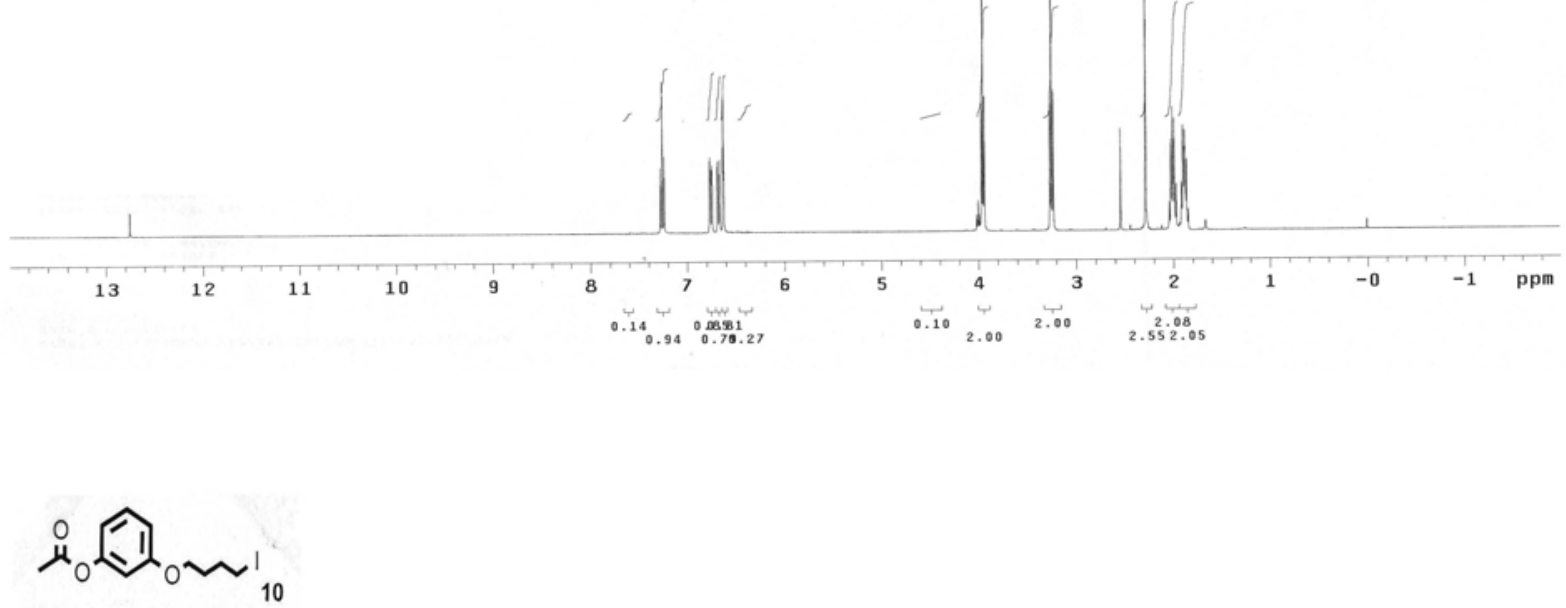

${ }^{13} \mathrm{C} \mathrm{NMR}, 400 \mathrm{MHz}, \mathrm{CD}_{3} \mathrm{OD}$

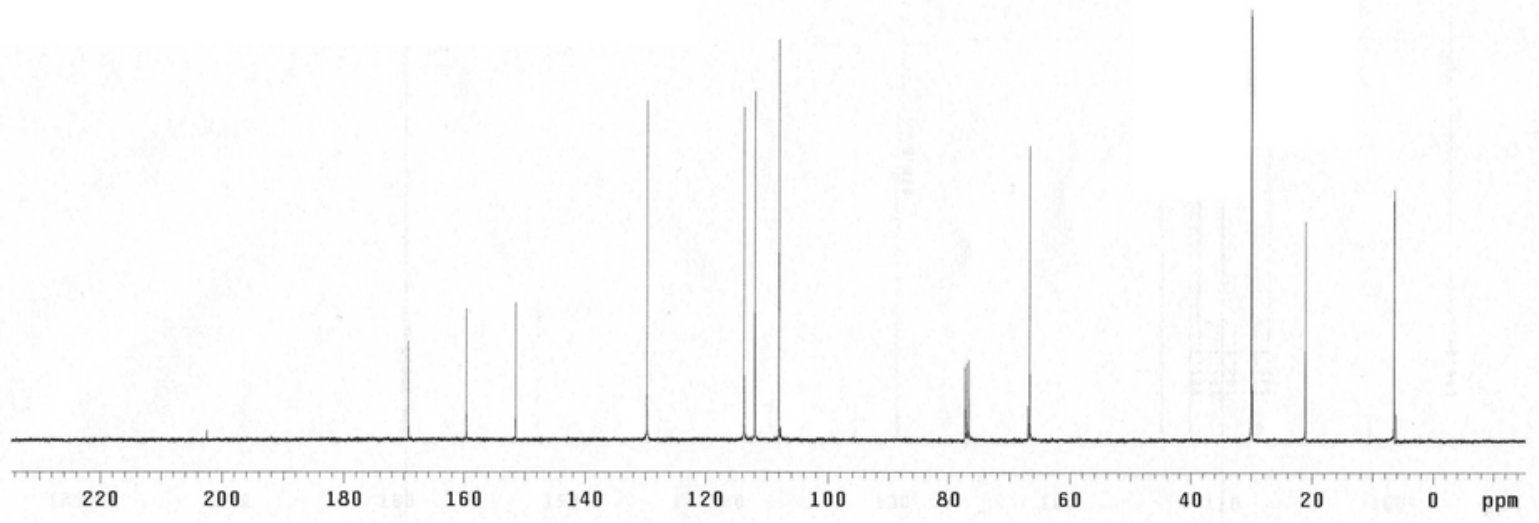

S30 


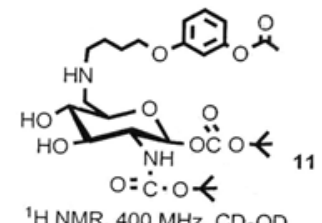

${ }^{1} \mathrm{HNMR}, 400 \mathrm{MHz}, \mathrm{CD}_{3} \mathrm{OD}$
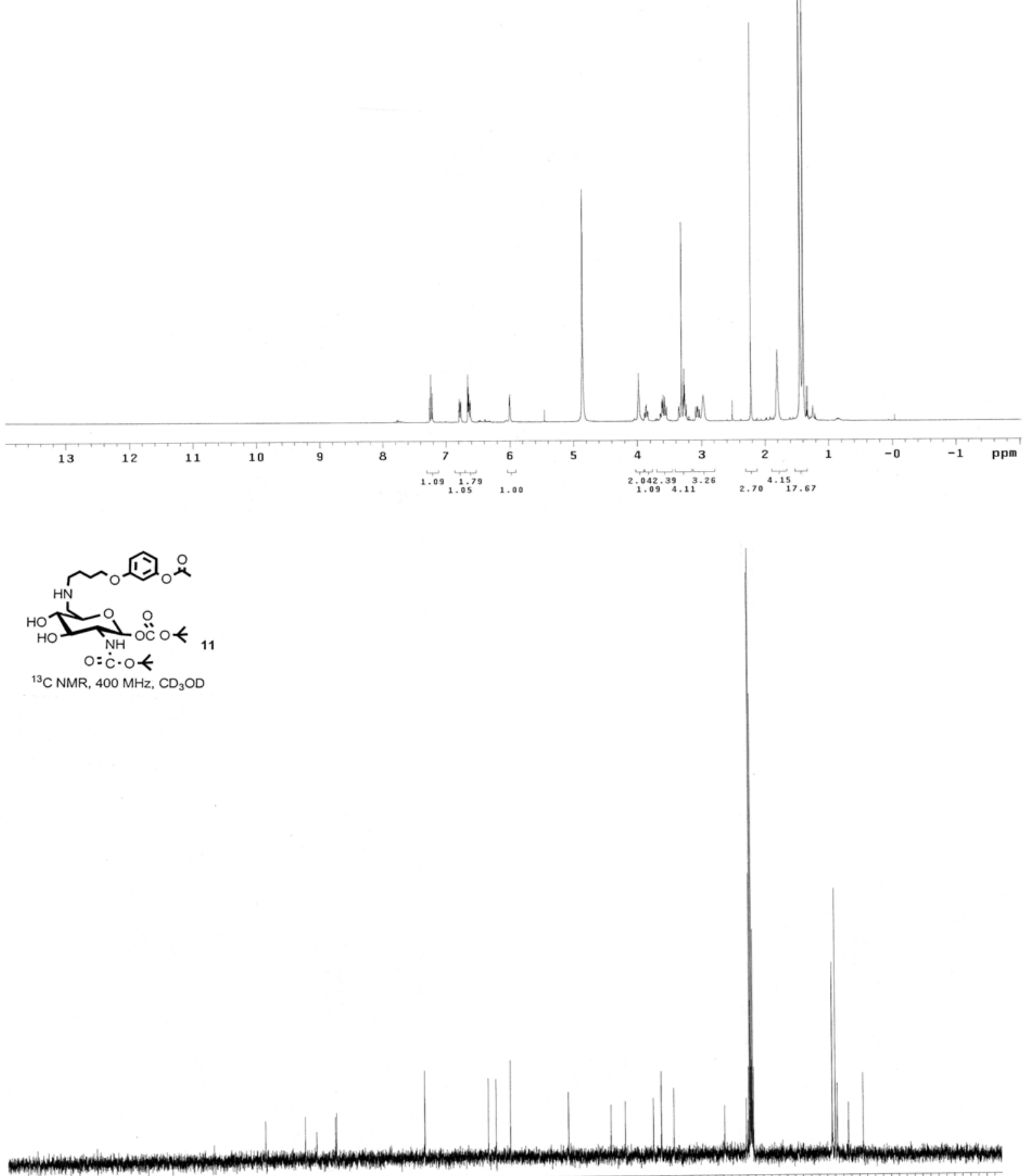

$220 \quad 200 \quad 180$

140

120

80

60

40

$200 \mathrm{ppm}$ 

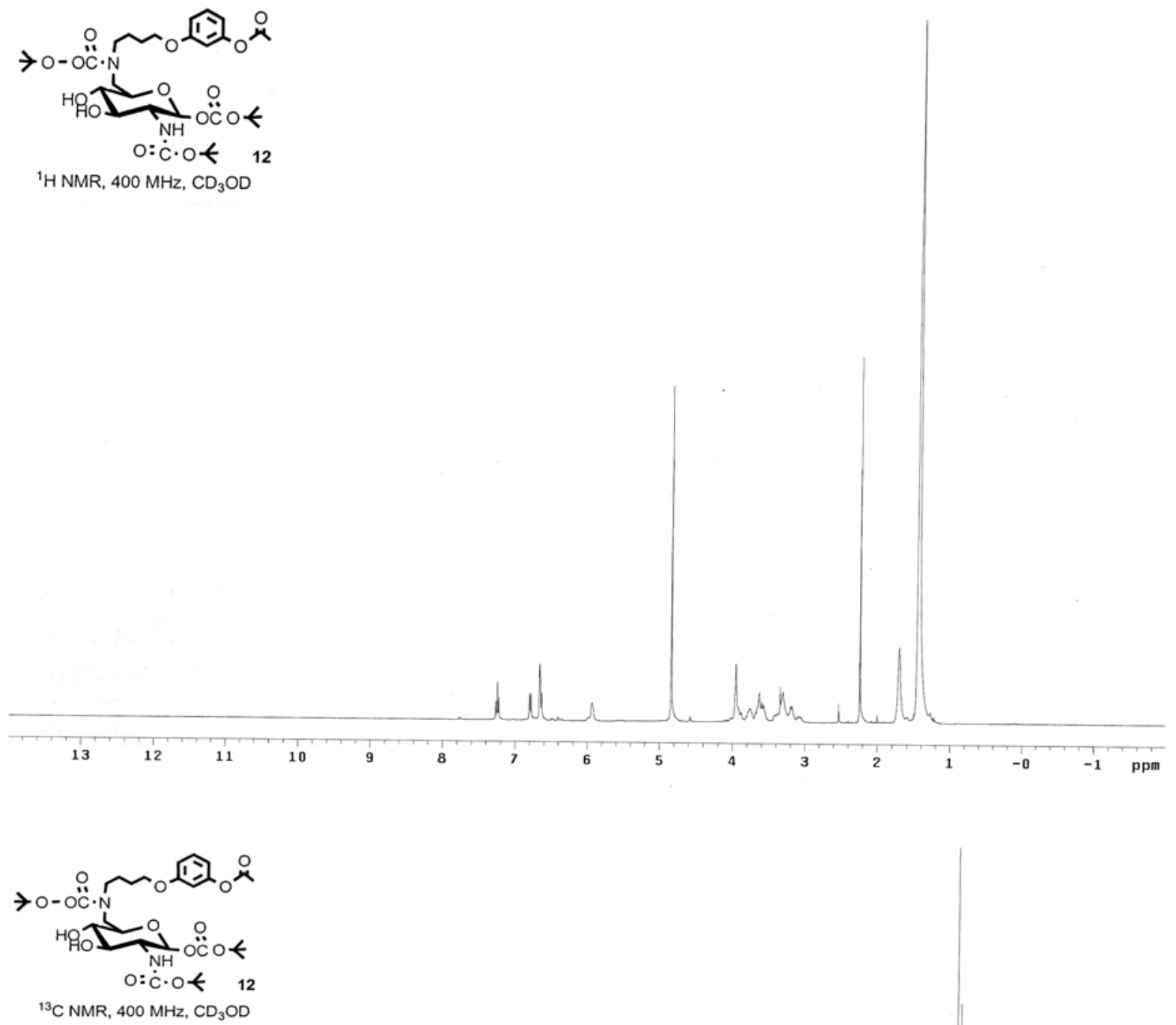

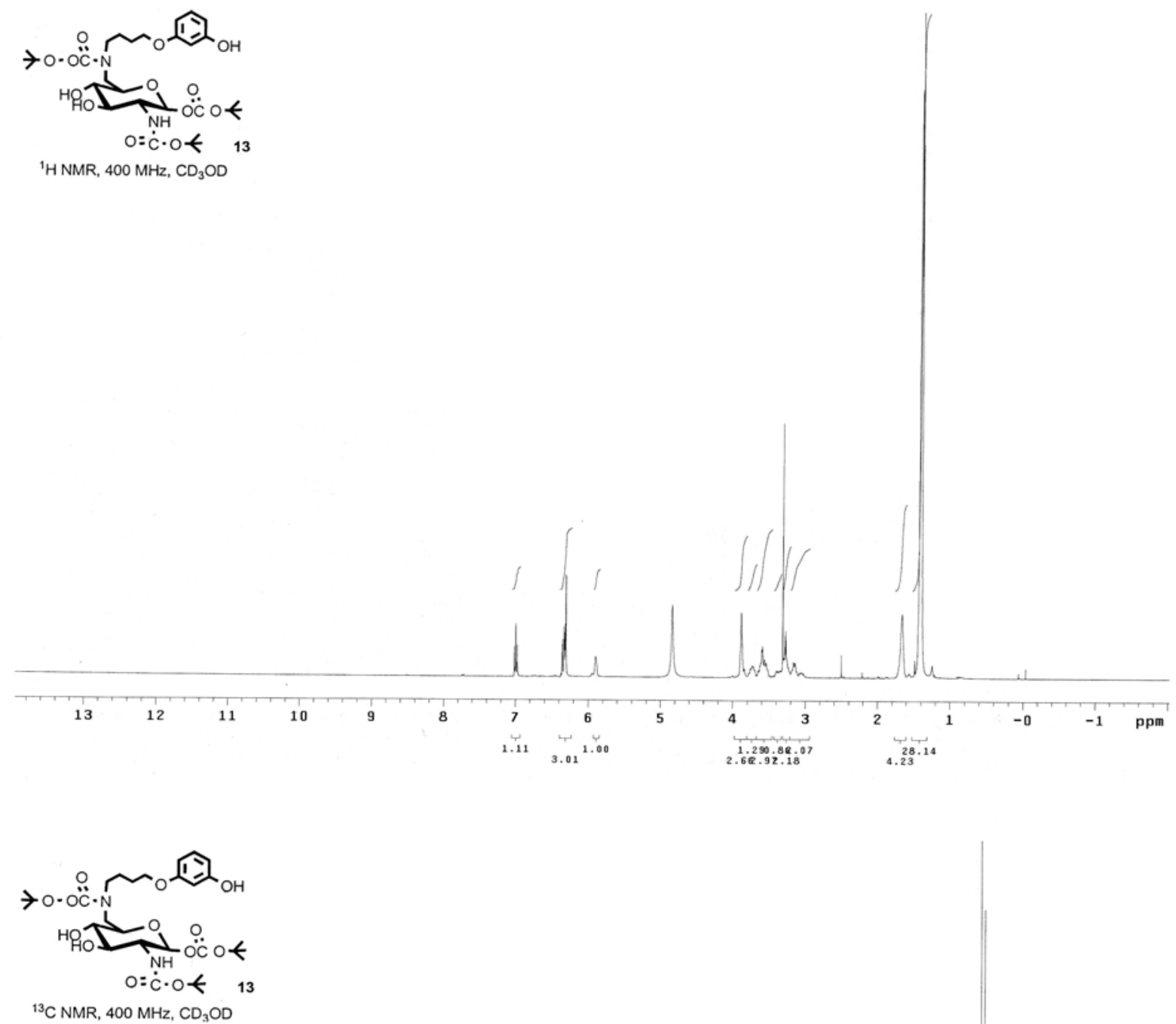

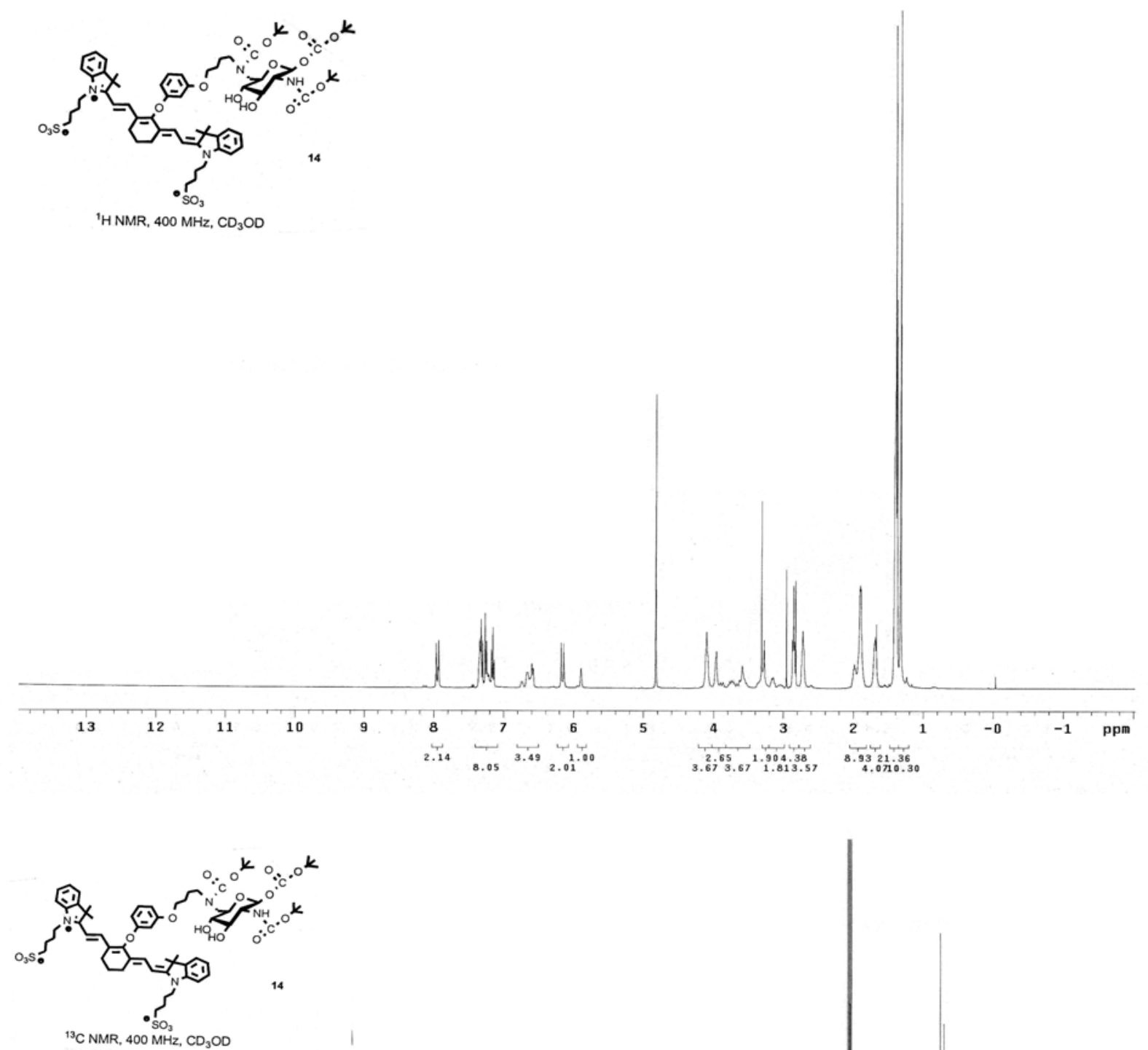

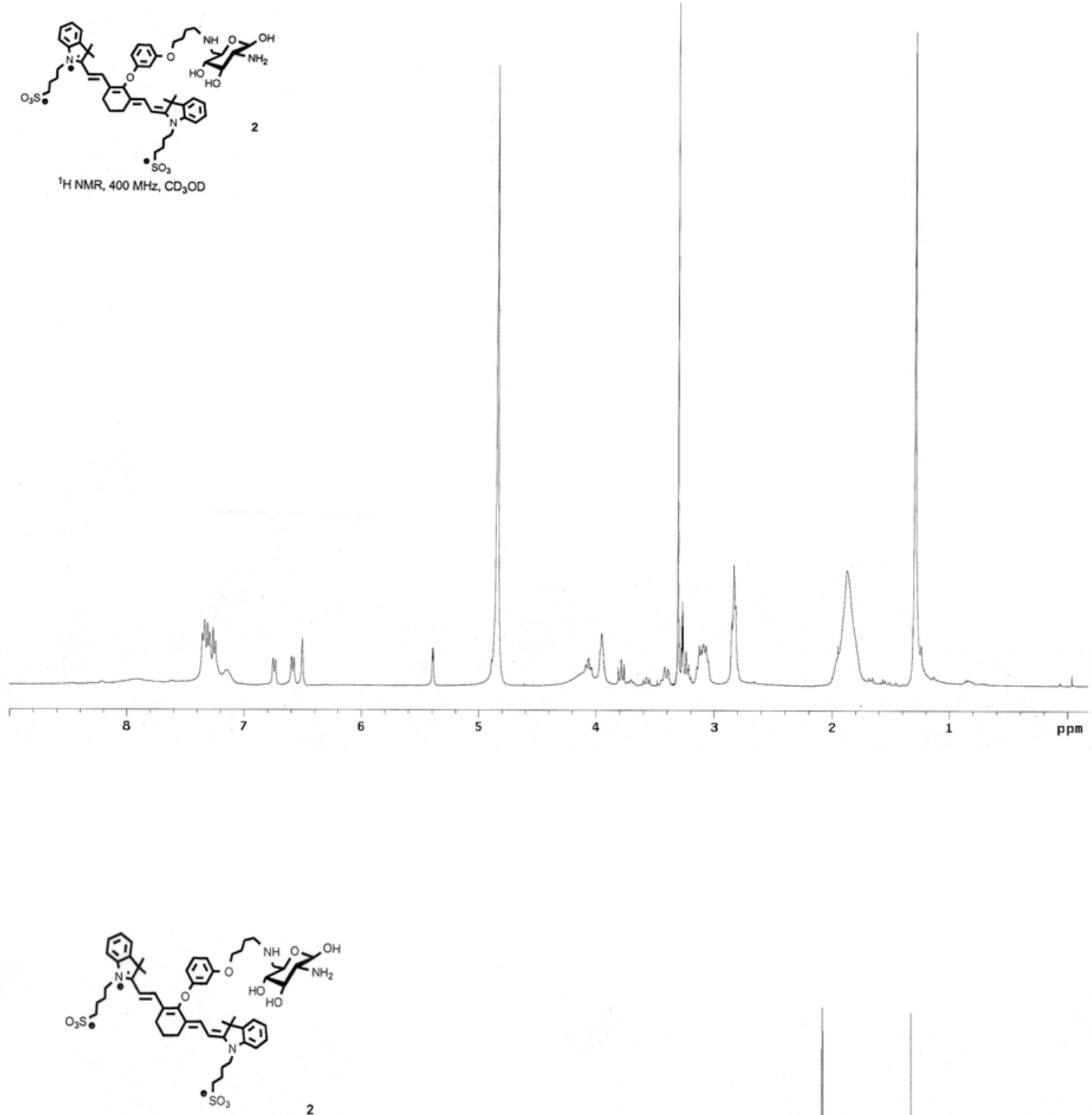

${ }^{13} \mathrm{C} \mathrm{NMR}, 400 \mathrm{MHz}, \mathrm{CD}_{3} \mathrm{OD}$

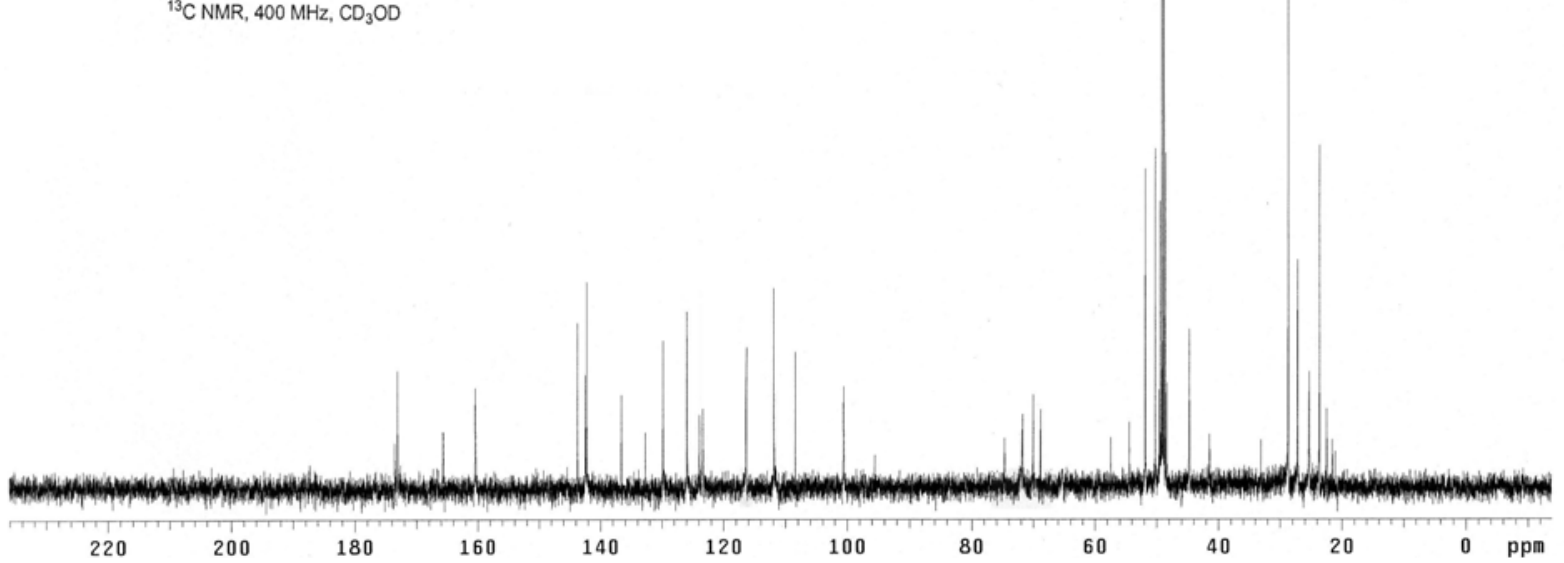




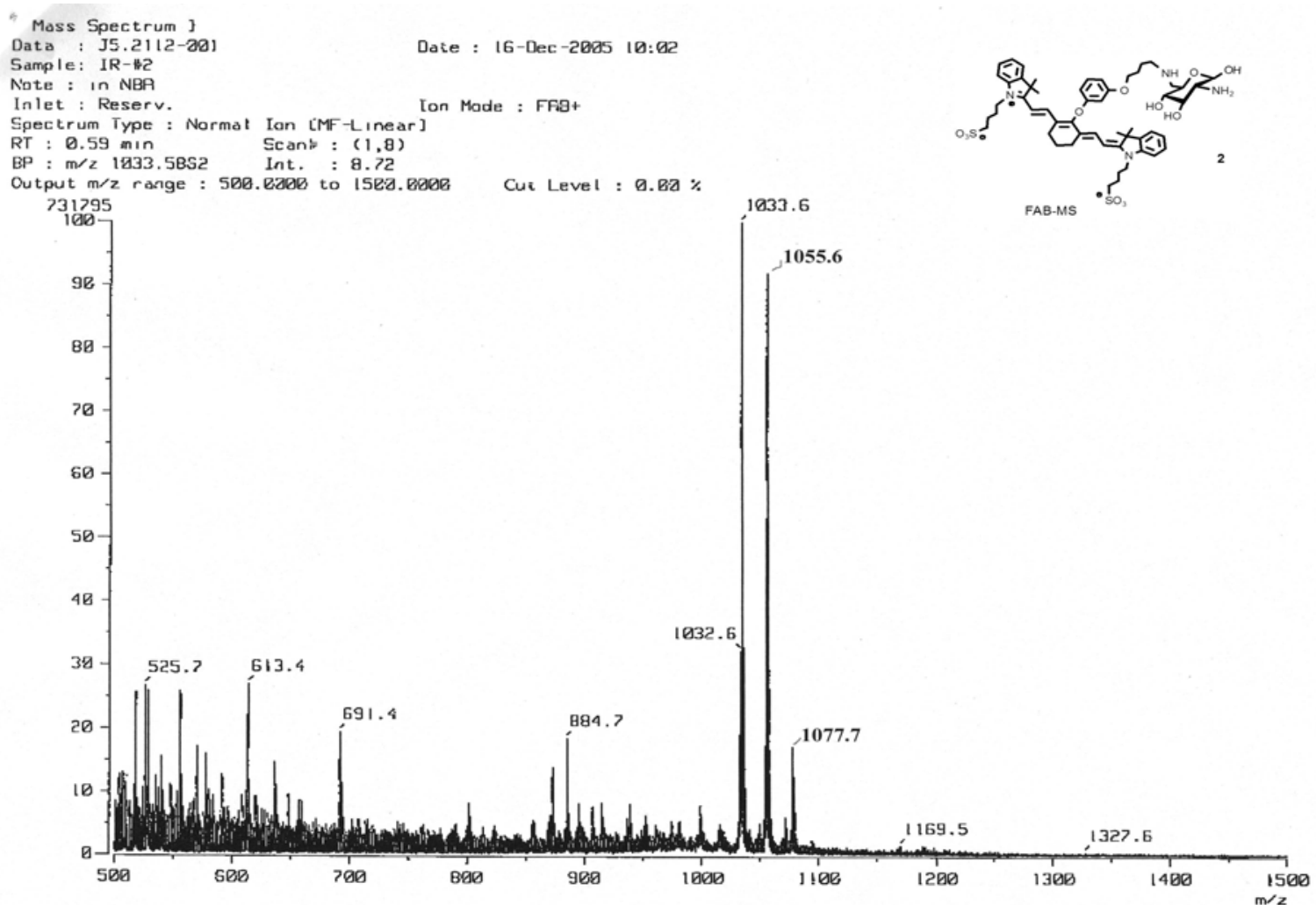



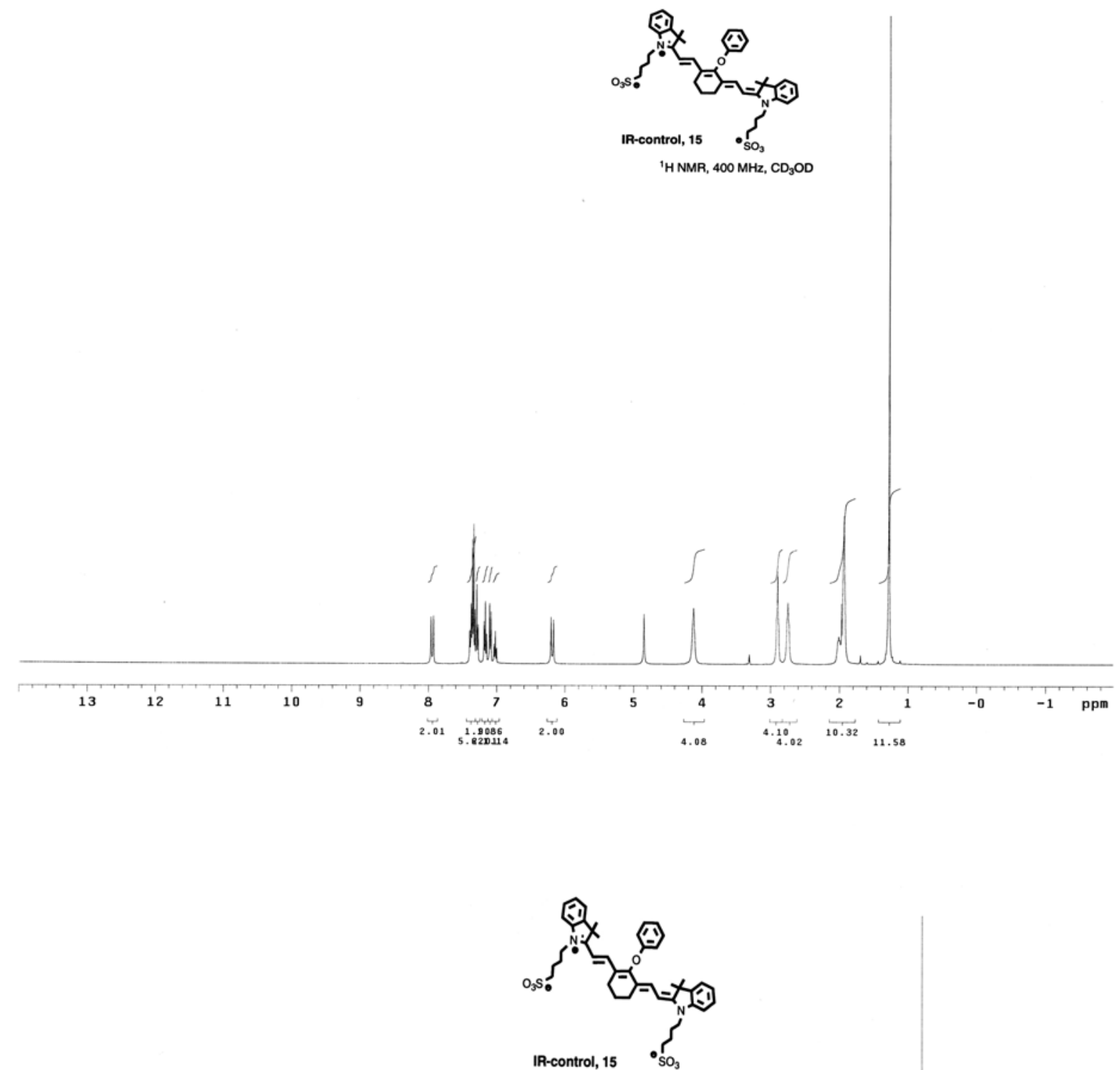

${ }^{13} \mathrm{C}$ NMR, $400 \mathrm{MHz}, \mathrm{CD}_{3} \mathrm{OD}$

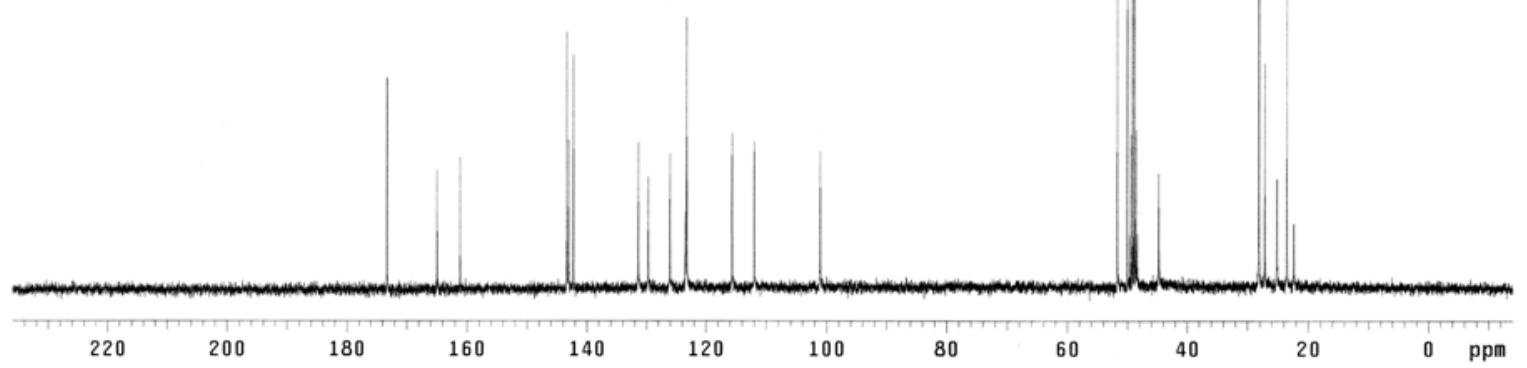




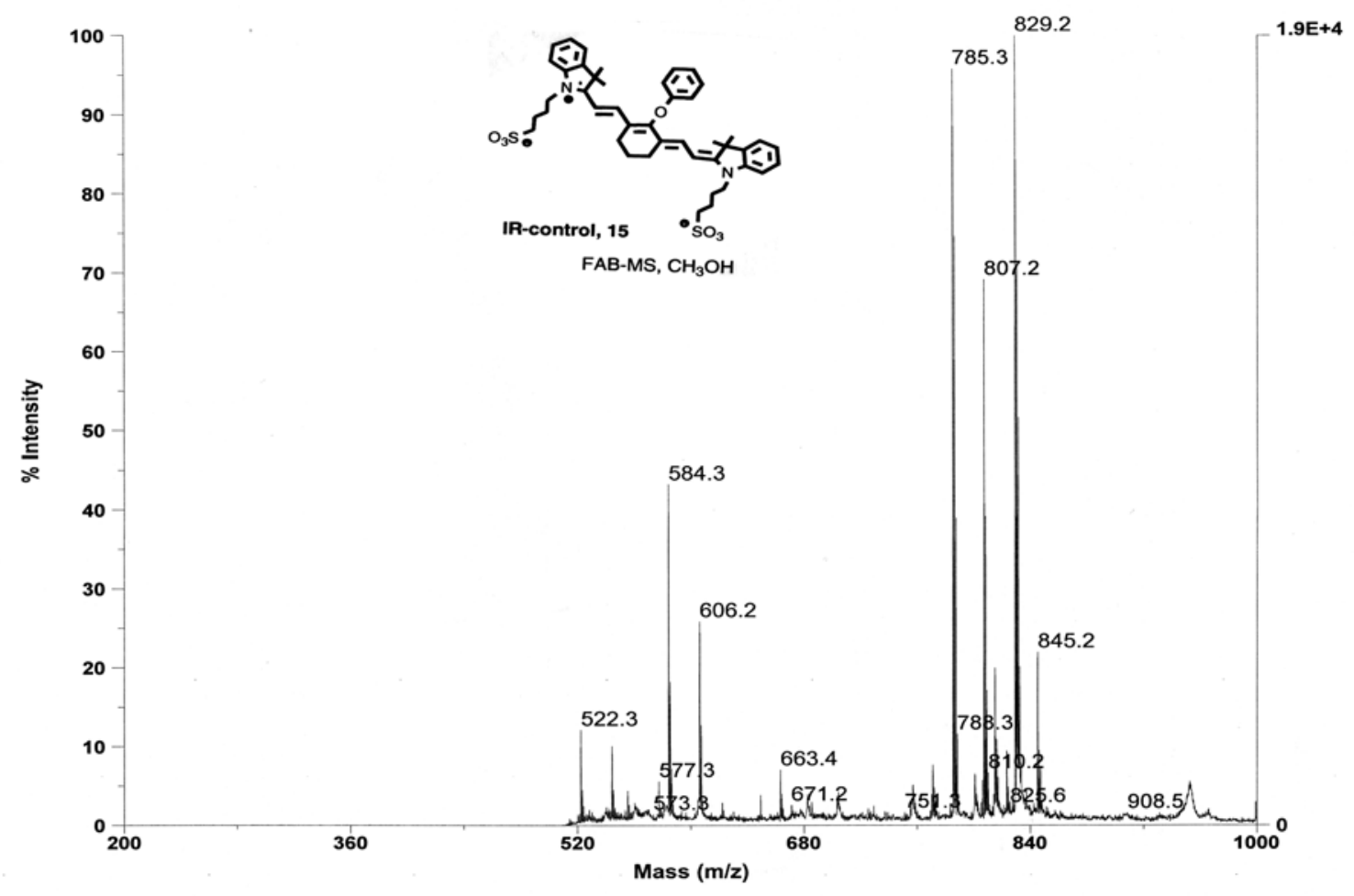

